Published in final edited form as:

ACS Chem Biol. 2019 August 16; 14(8): 1780-1792. doi:10.1021/acschembio.9b00342.

\title{
Molecular Determinants of the Intrinsic Efficacy of the Antipsychotic Aripiprazole
}

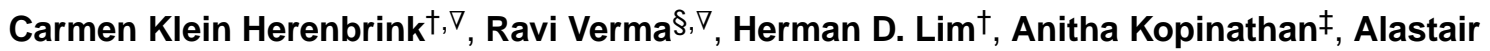 \\ Keen $^{\dagger}$, Jeremy Shonberg ${ }^{\ddagger}$, Christopher J. Draper-Joyce ${ }^{\dagger}$, Peter J. Scammells ${ }^{\ddagger}$, Arthur \\ Christopoulos $^{\dagger}$, Jonathan A. Javitch ${ }^{\|, \perp}$, Ben Capuano ${ }^{\ddagger}$, Lei Shi ${ }^{\star}, \S$, J. Robert Lane ${ }^{*}, \#, @$ \\ †Drug Discovery Biology, Monash University (Parkville campus), 399 Royal Parade, Parkville, VIC \\ 3052, Australia \\ ‡Medicinal Chemistry, Monash Institute of Pharmaceutical Sciences, Monash University (Parkville \\ campus), 399 Royal Parade, Parkville, VIC 3052, Australia \\ $\S$ Computational Chemistry and Molecular Biophysics Unit, National Institute on Drug Abuse- \\ Intramural Research Program, National Institutes of Health, 333 Cassell Drive, Baltimore, \\ Maryland 21224, United States \\ "Departments of Psychiatry and Pharmacology, Vagelos College of Physicians and Surgeons, \\ Columbia University, New York, New York 10032, United States \\ ${ }^{\perp}$ Division of Molecular Therapeutics, New York State Psychiatric Institute, New York, New York \\ 10032, United States \\ \#Division of Pharmacology, Physiology and Neuroscience, School of Life Sciences, Queen's \\ Medical Centre, University of Nottingham, Nottingham NG7 2UH, U.K. \\ $@$ Centre of Membrane Protein and Receptors, Universities of Birmingham and Nottingham, \\ United Kingdom
}

\section{Abstract}

Partial agonists of the dopamine $\mathrm{D}_{2}$ receptor $18\left(\mathrm{D}_{2} \mathrm{R}\right)$ have been developed to treat the symptoms of schizophrenia without causing the side effects elicited by antagonists. The receptor-ligand interactions that determine the intrinsic efficacy of such drugs, however, are poorly understood. Aripiprazole has an extended structure comprising a phenylpiperazine primary pharmacophore and a 1,2,3,4-tetrahydroquinolin-2-one secondary pharmacophore. We combined site-directed mutagenesis, analytical pharmacology, ligand fragments, and molecular dynamics simulations to

\footnotetext{
*Corresponding Authors Centre of Membrane Proteins and Receptors, Compare Office C101a, School of Life Sciences, Queens Medical Centre, University of Nottingham, Nottingham NG7 2UH, U.K. rob.lane@ nottingham.ac.uk. Telephone: +44 (0)115-8230468. Computational Chemistry and Molecular Biophysics Unit, National Institute on Drug Abuse-Intramural Research Program, National Institutes of Health, 333 Cassell Dr., Baltimore, MD 21224. lei.shi2@nih.gov. Telephone: +1(443)740-2774. $\nabla_{\text {C.K.H. and R.V. contributed equally to this work. }}$

ASSOCIATED CONTENT

Supporting Information

The Supporting Information is available free of charge on the ACS Publications website at DOI: 10.1021/acschem-bio.9b00342. Supplementary methods, including chemical synthesis, Supplementary Figures 1-3, Supplementary Tables 1-7, and supplementary references (PDF)

The authors declare no competing financial interest.
} 
identify the $\mathrm{D}_{2} \mathrm{R}$-aripiprazole interactions that contribute to affinity and efficacy. We reveal that an interaction between the secondary pharmacophore of aripiprazole and a secondary binding pocket defined by residues at the extracellular portions of transmembrane segments 1,2, and 7 determines the intrinsic efficacy of aripiprazole. Our findings reveal a hitherto unappreciated mechanism for fine-tuning the intrinsic efficacy of $\mathrm{D}_{2} \mathrm{R}$ agonists.

\section{Graphical Abstract}
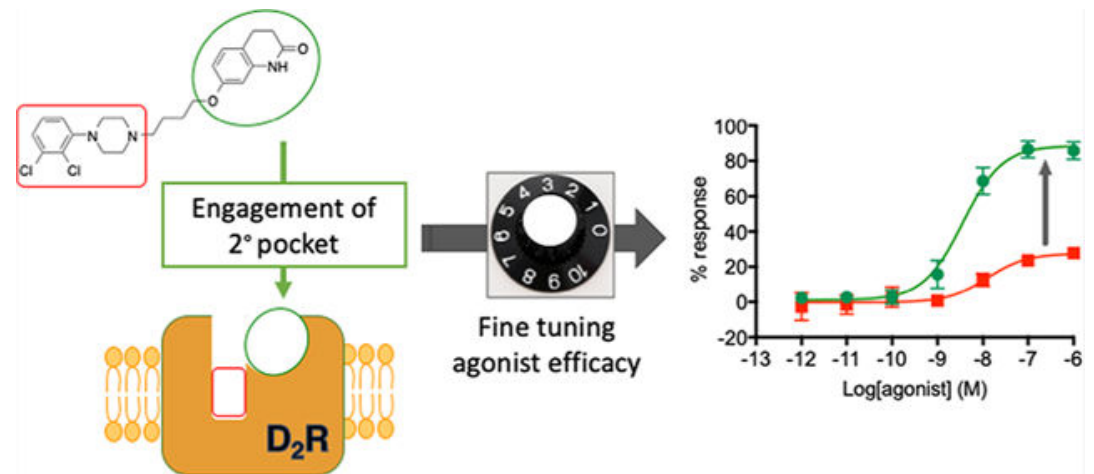

The dopamine $\mathrm{D}_{2}$ receptor $\left(\mathrm{D}_{2} \mathrm{R}\right)$, a class $A$ G protein-coupled receptor (GPCR), is the target of drugs that relieve symptoms of Parkinson's disease (agonists) and schizophrenia (partial agonists/antagonists). ${ }^{1}$ The antipsychotics aripiprazole, brexpiprazole, and cariprazine are $\mathrm{D}_{2} \mathrm{R}$ partial agonists. ${ }^{2-4}$ They are thought to act as functional antagonists in the striatum, where excessive dopamine activity is thought to cause positive symptoms, but to show agonist activity in the mesocortical pathway, where reduced dopamine activity is thought to be associated with negative symptoms and cognitive impairment. A partial agonist may also prevent the complete blockade of the nigrostriatal or tuberoinfundibular pathways, associated with extrapyramidal symptoms and elevated prolactin levels, respectively. ${ }^{5}$ However, why these partial agonists display antipsychotic efficacy while other $\mathrm{D}_{2} \mathrm{R}$ partial agonists have failed to do so remains unclear. It has been proposed that the low level of intrinsic activity elicited by aripiprazole gives sufficient functional antagonism for antipsychotic efficacy whereas other partial agonists with higher intrinsic activity, such as bifeprunox, failed in clinical development. ${ }^{6}$ Furthermore, the intrinsic activity of aripiprazole is apparently sufficient to avoid motor side effects and prolactinemia.

The crystal structures of the $\mathrm{D}_{2} \mathrm{R}, \mathrm{D}_{3} \mathrm{R}$, and $\mathrm{D}_{4} \mathrm{R}$, in complex with the antagonists risiperidone, eticlopride, and nemonapride, respectively, reveal the location of an orthosteric binding site (OBS) comprised of residues that are conserved in the dopamine $\mathrm{D}_{2}$-like receptors and are consistent with earlier findings of mutagenesis and molecular modeling studies. ${ }^{7-10}$ Despite the therapeutic utility of $\mathrm{D}_{2} \mathrm{R}$ full and partial agonists, our understanding of the ligand-receptor contacts that determine the degrees of intrinsic efficacy is limited. Agonist-bound class A GPCR crystal structures reveal different patterns of agonist-receptor interactions but common structural rearrangements in the extracellular part of the transmembrane (TM) bundle near the OBS upon receptor activation. ${ }^{11,12}$ These are translated into larger rearrangements at the cytoplasmic side of the receptor, including translation and rotation of TM5 and TM6 and relocation of TM3 and TM7. In particular, 
comparisons of class A GPCR crystal structures in active and inactive states, combined with molecular dynamics (MD) simulations, have highlighted the movement of a cluster of residues, Pro ${ }^{5.50}, \mathrm{Ile}^{3.40}$, and Phe ${ }^{6.44}$ (termed the "PIF motif", Ballesteros and Weinstein numbering system ${ }^{13}$ ), along with Leu/Val ${ }^{5.51}$ and $\operatorname{Trp}^{6.48}$ on receptor activation. The reconfigurations of these residues couple the conformational changes in the binding pocket to those at the intracellular coupling interface. ${ }^{14-16}$

Aripiprazole is comprised of a 4-(2,3-dichlorophenyl)-piperazine primary pharmacophore (PP) and a 1,2,3,4-tetrahydroquinolin-2-one secondary pharmacophore (SP) linked by a flexible butoxy linker. This extended structure is typical of ligands that are selective for dopamine D2-like receptors. ${ }^{7,17}$ Using the $\mathrm{D}_{3} \mathrm{R}$ crystal structure, ${ }^{7}$ we revealed a secondary binding pocket (SBP) that extended away from the OBS toward the extracellular ends of TM1-TM3 and TM7 and demonstrated that the interaction between this SBP and the aryl tail moiety of phenylpiperazine derivatives not only was an important determinant of subtype selectivity but could also modulate ligand efficacy through reorientation of the phenylpiperazine core within the SBP. ${ }^{18,19}$ Surprisingly, however, little is known about the binding mode of aripiprazole at the $\mathrm{D}_{2} \mathrm{R}$ and how this might determine its agonist efficacy. To address this, we combined MD simulations, mutagenesis, and analytical pharmacology to quantify agonist action in terms of both efficacy $(\tau)$ and functional affinity $\left(K_{\mathrm{A}}\right)$. Together, our studies reveal that the interaction between the 1,2,3,4-tetrahydroquinolin-2-one SP and the $\mathrm{D}_{2} \mathrm{R}$ SBP is a determinant of aripiprazole's intrinsic efficacy.

\section{RESULTS AND DISCUSSION}

\section{Aripiprazole and Dopamine Show Distinct Sensitivities to OBS Mutations.}

To interrogate the ligand-receptor interactions involved in agonist binding and the subsequent activation of the $\mathrm{D}_{2} \mathrm{R}$, we mutated residues within the OBS, the SBP, and the transmission switch of the $\mathrm{D}_{2} \mathrm{R}$. An enzyme-linked immunosorbent assay (ELISA) revealed no significant difference between the cell surface expression levels of the mutant and wildtype (WT) receptors (Supplementary Figure 1). We then determined the effect of each mutation on the dissociation constant $\left(\mathrm{p} K_{\mathrm{d}}\right)$ of $\left[{ }^{3} \mathrm{H}\right]$ spiperone and/or $\left[{ }^{3} \mathrm{H}\right]$ raclopride. A homologous competition binding assay revealed that none of the mutations had a significant effect on the $\mathrm{p} K_{\mathrm{d}}$ of $\left[{ }^{3} \mathrm{H}\right]$ spiperone (Supplementary Table 2) with the exception of $\mathrm{V} 91^{2.61} \mathrm{~A}$, $\mathrm{F} 360^{6.51} \mathrm{~A}$, and $\mathrm{F} 361^{6.52} \mathrm{~A}$, for which no detectable binding was observed. Of these three mutants, $\left[{ }^{3} \mathrm{H}\right]$ raclopride bound $\mathrm{V} 91^{2.61} \mathrm{~A}$ with WT affinity but was unable to bind $\mathrm{F} 360^{6.51} \mathrm{~A}$ and F361 ${ }^{6.52} \mathrm{~A}$ (Supplementary Table 2).

The binding affinities $\left(K_{\mathrm{i}}\right)$ of the agonists at the $\mathrm{D}_{2} \mathrm{R}$ were $\mathrm{t} 1$ determined in competition binding experiments (Table 1). To measure the functional impact of the mutations, we used inhibition of forskolin-induced cAMP production as a measure of $\mathrm{D}_{2} \mathrm{R} \mathrm{Ga} \mathrm{i}_{\mathrm{i}} \mathrm{o}_{\mathrm{o}} \mathrm{G}$ protein signaling. Many OBS mutations, however, abrogated the binding and/or functional activity of dopamine, which prevented us from quantifying the relative effect of these mutations on aripiprazole. We, therefore, extended our studies to ropinirole, an agonist that retained activity at many OBS mutations. We designed a sensitive cAMP assay using a low (300 nM) concentration of forskolin to give a greater dynamic range with which to quantify the deleterious effects of receptor mutants. In this assay, aripiprazole displayed a robust partial 
maximal response (80\%) relative to that of dopamine. This contrasts with the results of previous studies of aripiprazole using the same $\mathrm{CHO}$ cell background for which a much weaker relative maximal response was observed. ${ }^{2,20}$ Such differences reflect different receptor expression levels and assay sensitivities. Our data were fitted with an operational model of agonism to derive a transduction coefficient $\left(\tau / K_{\mathrm{A}}\right)$ of all three agonists, comprised of agonist efficacy $(\tau)$ and the functional affinity of the receptor when coupled to a specific signaling pathway $\left(K_{\mathrm{A}}\right) \cdot{ }^{21}$ Although we could not define these two separate parameters for the full agonists dopamine and ropinirole, in the case of the partial agonist aripiprazole, we could determine separate values of affinity and efficacy $\left[K_{\mathrm{A}}=17 \mathrm{nM}\right.$, and $\tau=5$ (Table 1)].

We first investigated the role of OBS residues (Table 1). Asp114 ${ }^{3.32}$ forms a salt bridge interaction with the positively charged nitrogen of dopaminergic ligands, and the D114.32 A mutation ablates agonist and antagonist binding. ${ }^{22} \mathrm{Val}^{3.33}$, $\mathrm{Cys}^{3.36}$, and $\mathrm{Thr}^{3.37}$ line the OBS in the $D_{2} R, D_{3} R$, and $D_{4} R$ structures, respectively. ${ }^{7,9,10}$ V115 $5^{3.33}$ A reduced the binding affinity of dopamine and aripiprazole but not that of ropinirole and decreased the transduction coefficients $\left(\tau / K_{\mathrm{A}}\right.$ ) of all ligands (Table 1$)$. In the case of aripiprazole, this effect was caused by a significant 8 -fold decrease in efficacy $(\tau)$. C1 $18^{3.36} \mathrm{~A}$ or T119.37 A had little effect on binding affinity $\left(K_{\mathrm{i}}\right)$ but significantly reduced the functional effect of all ligands, causing a $>50$-fold decrease in transduction coefficients $\left(\tau / K_{\mathrm{A}}\right)$ or abrogating activity altogether (Table 1).

The conserved TM5 serine residues have been shown to be important for agonist binding and action at all DR subtypes. ${ }^{23-27}$ In agreement with these previous studies, the binding affinity of dopamine was significantly reduced at $\mathrm{S} 193^{5.42} \mathrm{~A}, \mathrm{~S} 194^{5.43} \mathrm{~A}$, and $\mathrm{S} 197^{5.46} \mathrm{~A}$ by 120-, 4-, and 3-fold, respectively (Figure 1 and Table 1). The transduction $\mathrm{f} 1$ coefficient of dopamine was reduced at $\mathrm{S} 193^{5.42} \mathrm{~A}$ (1600-fold) and S1945.43 A (11-fold), whereas $\mathrm{S} 197^{5.46} \mathrm{~A}$ abolished its functional effect entirely (Figure 1 and Table 1$)$. The binding affinity and transduction coefficient of ropinirole were also significantly reduced at S193 ${ }^{5.42} \mathrm{~A}$ by 15 - and 930 -fold, respectively. $\mathrm{S} 194^{5.43} \mathrm{~A}$ had no effect on ropinirole affinity but caused a 20 -fold decrease in the transduction coefficient, whereas $S 197^{5.46} \mathrm{~A}$ had no effect. Interestingly, mutation of the TM5 serines did not decrease the efficacy $(\tau)$ of aripiprazole (Figure 1). Rather, S193.42 A caused a 3-fold increase in binding affinity and a 10 -fold increase in efficacy, whereas $\mathrm{S} 197^{5.46} \mathrm{~A}$ caused a 5-fold decrease in binding affinity with no effect on the functional response (Figure 1 and Table 1).

Residues within ECL2 form part of the $\mathrm{D}_{2} \mathrm{R}$ and $\mathrm{D}_{3} \mathrm{R}$ OBS. ${ }^{7,28}$ I184 ${ }^{\text {ECL2 }}$ A significantly reduced the binding affinity and transduction coefficient of dopamine (4- and 28-fold, respectively) (Table 1). None of the ECL2 mutations affected the binding affinity, functional affinity, or efficacy of aripiprazole (Table 1).

Residues 6.51 and 6.52 interact with the substituted aromatic ring of eticlopride in the $\mathrm{D}_{3} \mathrm{R}$ and the methoxy benzamide ring of nemonapride in the $\mathrm{D}_{4} \mathrm{R} .{ }^{7,9}$ None of the agonists displayed functional activity at $\mathrm{F} 360^{6.51} \mathrm{~A}$, and $\mathrm{F} 361^{6.52} \mathrm{~A}$ caused a significant decrease in the transduction coefficients of both ropinirole (9-fold) and dopamine (7-fold) (Figure 1 and Table 1). Residue 6.55 has been shown to be important for agonist binding and efficacy at the $\mathrm{D}_{2} \mathrm{R}$ and $\mathrm{D}_{3} \mathrm{R} .{ }^{7,27,29,30} \mathrm{H} 364^{6.55} \mathrm{~A}$ decreased the binding affinity (4-fold) and 
transduction coefficient (69-fold) of dopamine and the transduction coefficient (6-fold) of ropinirole but not its affinity. The $\mathrm{H} 364^{6.55} \mathrm{~F}$ mutation reduced the transduction coefficient of ropinirole (110-fold) and dopamine (28-fold), indicating that the imidazole side chain of His $364^{6.55}$ is important for the agonist action of these ligands (Table 1). Residues 6.58 and 6.59 line the OBS. ${ }^{30} \mathrm{In}$ the $5 \mathrm{HT}_{2 \mathrm{~B}}$ receptor, these residues form hydrophobic contacts with ergotamine that are important for its biased action. ${ }^{31} \mathrm{~N} 367^{6.58} \mathrm{~A}$ caused a 3 -fold decrease in the binding affinity and a 10-fold decrease in the transduction coefficient of dopamine only (Table 1). $1368^{6.59} \mathrm{~A}$ decreased the transduction coefficient of ropinirole by 5 -fold. Notably, mutation of these TM6 residues ( $3361^{6.52} \mathrm{~A}, \mathrm{H} 364^{6.55} \mathrm{~A} / \mathrm{F}, \mathrm{N} 367^{6.58} \mathrm{~A}$, or I368 $8^{6.59} \mathrm{~A}$ ) did not change the affinity or efficacy of aripiprazole (Figure 1 and Table 1). Mutation of $\mathrm{Thr} 383^{7.39}$, a residue shown to contribute to aminergic receptor ligand binding, ${ }^{8}$ did not change the binding affinity of the three agonists but decreased the transduction coefficient of ropinirole (29-fold) while it increased that of aripiprazole 5-fold.

In summary, we identified OBS residues that contribute to the efficacy of all three agonists but found mutations in ECL2 (I184 $\left.{ }^{\mathrm{ECL} 2} \mathrm{~A}\right), \mathrm{TM} 5\left(\mathrm{~S} 193^{5.42} \mathrm{~A}, \mathrm{~S} 194^{5.43} \mathrm{~A}\right.$, and $\mathrm{S} 197^{5.46} \mathrm{~A}$ ), and TM6 $\left(\mathrm{F} 361^{6.52} \mathrm{~A}, \mathrm{H} 364^{6.55} \mathrm{~A}, \mathrm{~N} 367^{6.58} \mathrm{~A}\right.$, or $\left.\mathrm{I} 368^{6.59} \mathrm{~A}\right)$ that had deleterious effects on the functional effect of dopamine and ropinirole but no effect on the efficacy of aripiprazole. Differential engagements of the TM5 serines (at positions 5.42, 5.43, and 5.46) and His ${ }^{6.55}$ by $\mathrm{D}_{2} \mathrm{R}$ agonists have been suggested to underlie differences in efficacy through the stabilization of distinct receptor conformations. ${ }^{27,29}$ In the case of aripiprazole, rather than deleterious effects, the $\mathrm{S}^{5.46} \mathrm{~A}, \mathrm{~F}^{6.52} \mathrm{~A}$, and $\mathrm{H}^{6.55} \mathrm{~A}$ mutations caused a modest increase in efficacy. Interestingly, $\mathrm{S}^{5.42} \mathrm{~A}$ and $\mathrm{S}^{5.46} \mathrm{~A}$ mutations caused decreases in the affinity and transduction coefficient of dopamine, in agreement with previous studies, whereas the $\mathrm{S}^{5.46} \mathrm{~A}$ mutation had no effect on ropinirole. In a previous study, our MD simulations found that $\mathrm{N}-1$ of sumanirole, an agonist that is structurally similar to ropinirole, forms a hydrogen bond with the side chain of $\mathrm{Ser}^{5.42}$ but no interaction with $\mathrm{Ser}^{5.46}$ was observed. ${ }^{32}$

Ropinirole might adopt a similar orientation, but further simulations are required to confirm this hypothesis.

\section{Transmission Switch Residues Are Required for Agonist Action at the D2R.}

Comparison of the active and inactive structures of rhodopsin and the adenosine $\mathrm{A}_{2 \mathrm{~A}}, \beta_{2}$ adrenergic, and $\mu$ opioid receptors revealed rearrangement of a cluster of hydrophobic and aromatic residues (including residues 3.40, 5.50, 5.51, 6.44, and 6.48) in the TM3-TM5TM6 motif as a common feature of class A GPCR activation. ${ }^{11,12,15} \mathrm{I} 122^{3.40}$ is part of the conserved $\mathrm{P}^{5.50}-\mathrm{I}^{3.40}-\mathrm{F}^{6.44}$ motif that undergoes structural rearrangement upon receptor activation to allow the outward movement of TM6. The I122 $2^{3.40}$ A mutation had no significant effect on the binding affinity of the agonists but abrogated functional activity. The F202 ${ }^{5.51}$ A mutation caused a significant reduction in the binding affinity of dopamine and aripiprazole [6- and 3-fold, respectively (Table 1)]. Aripiprazole displayed no agonism with this mutation, and ropinirole and dopamine displayed $>100$-fold lower transduction coefficients (Table 1). Thus, all three D2R agonists require conformational rearrangement of transmission switch residues to exert their agonistic effect. While F202 $2^{5.51}$ does not form part of the OBS, the F202 5.51 A mutation may modulate the conformation of the OBS causing the loss of affinity of dopamine and aripiprazole but not that of ropinirole. 
Interestingly, the recent D2R crystal structure obtained in complex with the antagonist risperidone included the $\mathrm{I} 122^{3.40} \mathrm{~A}$ mutation as one of three thermostabilizing mutations. ${ }^{10}$ This mutation likely exerts its thermostabilizing effect by preventing the isomerization of the receptor into the active state.

\section{Molecular Dynamics Simulations Reveal an Extended Pose of Aripiprazole.}

To characterize and dissect the contributions of residues from the OBS and SBP to the binding pose of aripiprazole, we performed a computational modeling and simulation study of $\mathrm{D}_{2} \mathrm{R}$ models in complex with aripiprazole. From the initial docking results, we chose several poses of aripiprazole with its quinoline moiety oriented in various directions in the extracellular vestibule (EV) of $\mathrm{D}_{2} \mathrm{R}$ (see Methods). We then collected multiple MD trajectories for each pose (Supplementary Table 1) and sought to identify a convergent trend of the ligand dynamics in the binding site.

Similar to the partial agonists with a 2,3-diCl-phenylpiperazine PP that we have characterized previously in D3R models, ${ }^{18}$ the PP of aripiprazole adopts a pose that is relatively parallel to the membrane and close to Ser $193^{5.42}$ but does not form an H-bond with Ser $193^{5.42}$. In all our simulations, Ser $197^{5.46}$ forms a H-bond to the backbone carbonyl of Ser193 ${ }^{5.42}$. Thus, the $\mathrm{S} 193^{5.42}$ A mutation may lead to an optimized hydrophobic interaction and slightly improve the affinity, whereas the Ser $197^{5.46}$ A mutation disrupts the local conformation of TM5 and results in a slightly decreased affinity. In such a pose, both rings of 2,3-diCl-phenylpiperazine are tightly packed with Phe $360^{6.51}$, and it is expected that the $\mathrm{F} 360^{6.51}$ A mutation would destabilize the observed orientation of the phenylpiperazine. Thus, this pose of the PP within the $\mathrm{D}_{2} \mathrm{R}$ OBS is in agreement with our mutagenesis results.

For the SP and the flexible butoxy linker, however, we found that our simulations from different starting poses and multiple trajectories converged to two distinct poses in the EV, depending on the orientation of the highly conserved $\operatorname{Trp} 384^{7.40}$. When $\operatorname{Trp} 384^{7.40}$ faces the lipid as in the $\mathrm{D}_{3} \mathrm{R}$ structure, the quinoline ring occupies a cavity at the interface among TM1, TM2, and TM7 and is in contact with Leu41 $1^{1.39}$, Val91 ${ }^{2.61}$, and Trp384 $4^{7.40}$ (Figure 2C). In contrast, when the indole ring of Trp384 ${ }^{7.40}$ rotates inward between the side chains of Val91 $1^{2.61}$ and Leu41 $1^{1.39}$, the quinoline ring can no longer extend into this cavity but rather tilts toward ECL2 and TM3, forming a weak interaction with Glu95 $5^{2.65}$ (Figure 2D). Such an inward orientation of Trp384 7.40 is observed in most of the crystal structures of aminergic receptors. ${ }^{33}$ While Trp $384^{7.40}$ of the $\mathrm{D}_{3} \mathrm{R}$ faces the lipid, that of the $\mathrm{D}_{2} \mathrm{R}$ structure is in an intermediate position, and in our simulations, we observed that this residue can adopt both inward and outward orientations. 7,10

\section{The SP of Aripiprazole Confers an Increase in Efficacy.}

To explore how the interaction of the SP of aripiprazole with the $\mathrm{D}_{2} \mathrm{R}$ SBP might influence affinity and efficacy, we characterized a series of progressively extended fragments of aripiprazole incorporating either the PP or the SP. The introduction of the alkyl or alkoxy spacers (compounds 2-4) into the PP 2,3-dichloropheylpiperazine fragment (DCPP, 1) conferred 32-115-fold increases in binding affinity (Figure 3 and Table 2). Incorporation of the 1,2,3,4-tetrahydroquinolin-2-one (THQ) moiety of aripiprazole enhanced the binding 
affinity by a further 22-fold compared to that of the methoxybuty-1-substituted derivative (4). Fragments containing the SP were able to displace the radioligand only upon inclusion of an ionizable nitrogen atom within its structure (Supplementary Table 3). In functional studies, this time using a bioluminescence resonance energy transfer (BRET) biosensor to measure cAMP levels, the incorporation of alkyl or alkoxy spacers conferred a $\leq 17$-fold increase in functional affinity as compared to that of DCPP, although a further increase in functional affinity was not observed upon incorporation of the THQ moiety. The DCPP fragment of aripiprazole displayed a weak intrinsic efficacy, in agreement with previously published data, ${ }^{18}$ an effect conferred through interaction of the PP with the OBS as shown by our MD simulations. The incorporation of a propyl linker (2) caused a 2-fold decrease in efficacy, whereas the butyl linker (3) and butoxy linker (4) derivatives displayed a level of efficacy similar to that of DCPP (Figure 3 and Table 2). Strikingly, the incorporation of the THQ moiety (to generate aripiprazole) caused a 10-fold increase in efficacy.

In our previous study, we observed that the DCPP core of R22 could be replaced with a 2methoxyphenylpiperazine (2MeOPP) core with little change in efficacy or affinity at the D2R. ${ }^{18}$ We hypothesized that addition of the 7-butoxy-1,2,3,4-tetrahydroquinolin-2-one substituent of aripiprazole to the $2 \mathrm{MeOPP}$ core (11) would cause an increase in both affinity and efficacy $(\tau)$. The addition of an N-butyl substitution conferred a 32-fold increase in affinity, whereas the addition of the 7-butoxy-1,2,3,4-tetrahydroquinolin-2-one substitution (13) conferred a 2600-fold higher affinity than the $2 \mathrm{MeOPP}$ core to yield an extended ligand with the same affinity as aripiprazole (Figure 2 and Table 2). Importantly, we observed that the addition of the 7-butoxy-1,2,3,4-tetrahydroquinolin-2-one substituent caused 26- and 10fold increases in efficacy $(\boldsymbol{\tau})$ as compared to those of the $2 \mathrm{MeOPP}(\mathbf{1 1})$ and the N-butyl substituent (12), respectively (Figure 3 and Table 2). Thus, the linking of the 7butoxy-1,2,3,4-tetrahydroquinolin-2-one SP to the 2MeOPP PP to generate a novel partial agonist 357 results in increases in both efficacy and affinity.

\section{Interaction with SBP Residues Determines the Efficacy of Aripiprazole.}

Our results show that the interaction of the SP with the SBP contributes to the affinity and, more surprisingly, the efficacy of aripiprazole. We used mutagenesis to explore the SBP residues that contribute to this interaction. In agreement with the interaction of the SP with SBP residues, the binding affinity of aripiprazole was significantly reduced by SBP mutations $\mathrm{W} 90^{2.60} \mathrm{~A}$ (5-fold), V91 ${ }^{2.61} \mathrm{~A}$ (8-fold), and $\mathrm{E} 95^{2.65} \mathrm{~A}$ (3-fold) (Table 3). The $\mathrm{V} 91^{2.61} \mathrm{~A}$ mutation caused a 11-fold reduction in the transduction coefficient of aripiprazole, whereas the $\mathrm{E} 95^{2.65} \mathrm{~A}$ mutation resulted in a 11-fold reduction in its functional affinity $\left(K_{\mathrm{A}}\right)$ (Figure 1 and Table 3). While the V91 $2.61 \mathrm{~A}$ and $\mathrm{E} 95^{2.65} \mathrm{~A}$ mutations had no effect on the two smaller agonists, the $\mathrm{W} 90^{2.60} \mathrm{~A}$ mutation reduced the transduction coefficients of ropinirole (14-fold) and dopamine (6-fold) and the binding affinity of dopamine (6-fold). The $\mathrm{E} 95^{2.65} \mathrm{~A}, \mathrm{~V} 91^{2.61} \mathrm{~A}$, and $\mathrm{L} 41^{1.39} \mathrm{~A}$ mutations did not change the affinity of the DCPP fragment (Table 2). The F110 ${ }^{3.28}$ A mutation significantly reduced the binding affinity of all three agonists and the transduction coefficients of dopamine and ropinirole but not that of aripiprazole (Table 3). The L $41^{1.39}$ A mutation increased the binding affinity of ropinirole and aripiprazole (5-fold) but had no significant effect on the binding affinity of dopamine (Figure 1 and Table 3 ). Strikingly, this mutation caused a 5-fold decrease in the efficacy ( $\tau$ ) 
of aripiprazole, whereas the transduction coefficients of the smaller agonists were not significantly changed (Table 3). Val91 2.61 and Phe $110^{3.28}$ are in close contact with the butoxy linker of aripiprazole in both of the SP poses obtained with our MD simulations (Figure 2), and these interactions can be correlated to the negative impact of the $\mathrm{V} 91^{2.61} \mathrm{~A}$ or $\mathrm{F} 110^{3.28} \mathrm{~A}$ mutation on aripiprazole affinity. We extended our MD simulations to compare the pose of aripiprazole at the WT and $\mathrm{L} 41^{1.39}$ A mutant. The $\mathrm{L} 41^{1.39}$ A mutation is associated with a higher propensity for inward rotation of Trp384 ${ }^{7.40}$ (Figure 2E,F and Supplementary Figure 1), which affects the orientation of Glu95 2.65 and Tyr $37^{1.35}$. Interestingly, Trp $384^{7.40}$, Tyr37 $7^{1.35}$, and Glu $95^{2.65}$ form an interaction network only in the mutant simulations (Figure 2F and Supplementary Figure 1). Thus, our simulations indicate that the orientation of the SP toward ECL2 and TM3 is favored in the L41 ${ }^{1.39}$ A mutant.

To compare our data with the functional data obtained with the various fragments of aripiprazole (Table 2), we used a BRET biosensor to measure the inhibition of cAMP. In this assay, dopamine and aripiprazole displayed significant 4- and 5-fold decreases in transduction coefficients at the L41 ${ }^{1.39}$ A mutant, respectively (Figure 4 and Supplementary Table 4). The latter effect was caused by a 5 -fold decrease in aripiprazole efficacy ( $\tau$ ) (Figure 4J), similar to changes observed in the Alpha-screen cAMP assay. It is noteworthy that the efficacy of aripiprazole at this mutant was equivalent to that of the DCPP fragment at the WT receptor, suggesting that the increase in efficacy conferred by the SP of aripiprazole requires Leu $41^{1.39}$. To determine whether the decreased transduction coefficient of dopamine at L41 ${ }^{1.39} \mathrm{~A}$ was caused by a decrease in functional affinity or efficacy, we treated cells with increasing concentrations of phenoxybenzamine to alkylate cell surface $\mathrm{D}_{2}$ Rs prior to stimulation with an agonist. We applied the operational model of agonism to these data to determine the functional affinity and efficacy of dopamine and ropinirole (Figure 4 and Supplementary Table 4). The L $41^{1.39}$ A mutation caused a 10-fold decrease in dopamine functional affinity $\left(K_{\mathrm{A}}\right)$ but no change in efficacy $(\tau)$ (Figure $4 \mathrm{H}, \mathrm{K}$ and Supplementary Table 4 ). The functional affinity and efficacy of ropinirole were unaffected by this mutation (Figure 4I,L and Supplementary Table 4).

As described above, Leu $41^{1.39}$ directly affects the rotation of Trp3847.40 (Figure 2). To explore the interaction between Trp384 $4^{7.40}$ and Leu $41^{1.39}$, either Trp384 7.40 or both residues were mutated to alanine. The action of all agonists was compromised at the double mutant because of its low level of cell surface expression (Supplementary Figure 3). The W3847.40 A mutation caused significant decreases in dopamine (5-fold) and ropinirole (3-fold) transduction coefficients but had no effect on that of aripiprazole (Figure 4 and Supplementary Table 4). This is consistent with our proposal that the aripiprazole pose shown in Figure $2 \mathrm{C}$ may be more relevant to its intrinsic efficacy, as the W384.40 A mutation is unlikely to have a negative impact on this pose when Trp384 faces lipids. In addition, the preference of the aripiprazole pose in the L41 ${ }^{1.39}$ A mutant, which is coordinated with the inward rotation of Trp384 (Figure 2F), supports the idea that the impact of this remote TM1 mutation may be partially mediated by $\operatorname{Trp} 384^{7.40}$.

We explored the effect of adding bulk and aromaticity to the SBP by mutating both V91 2.61 and $\mathrm{L} 41^{1.39}$ to phenylalanine. $\mathrm{L} 41^{1.39} \mathrm{~F}$ had no effect. V91 ${ }^{2.61} \mathrm{~F}$ caused $35-, 30-$, and $170-$ fold decreases in the transduction coefficients of dopamine, ropinirole, and aripiprazole, 
respectively (Figure 4F and Supplementary Table 4). This mutation caused decreases in the functional affinity (14-fold) and efficacy (11-fold) of aripiprazole. Leu41 $1^{1.39}$ and Val91 ${ }^{2.61}$ directly interact (Figure $2 \mathrm{C}$ ). The double mutation $\left(\mathrm{L} 41^{1.39} \mathrm{~A} / \mathrm{V} 91^{2.61} \mathrm{~A}\right)$ caused a 10 -fold decrease in the transduction coefficient of dopamine and ropinirole but a much greater 49fold decrease in that of aripiprazole, driven by a 42-fold decrease in efficacy (Figure 4I and Supplementary Table 4). In contrast, this double mutation decreased the functional affinity (Figure $4 \mathrm{H}$ and Supplementary Table 4 ) of dopamine by 5 -fold and had no significant effect on dopamine efficacy.

Together, these data indicate that the direct interaction of the SP of aripiprazole with the $\mathrm{D}_{2} \mathrm{R}$ SBP contributes to its intrinsic efficacy. The addition of the SP to the phenylpiperazine PP conferred a significant increase in efficacy, and mutations within the SBP modulated the activity of aripiprazole. The mutation of Leu $41^{1.39}$, a SBP residue distal to the OBS, significantly decreased the efficacy of aripiprazole in all signaling pathways but increased its binding affinity. Furthermore, the increase in efficacy conferred by the addition of the SP to the SBP was lost at the L41 ${ }^{1.39}$ A mutant. Thus, the increase in efficacy caused by the interaction of the SP with the SBP appears to be dependent on Leu41 $1^{1.39}$. Our MD simulations predicted two distinct orientations of the SP, one in which the SP occupies the SBP (contacting Leu41 ${ }^{1.39}$, Val91 $473^{2.61}$, and Glu95 ${ }^{2.65}$ ) and one in which the SP extends toward TM3. Our simulations show that the L41 1.39A mutation promotes the latter orientation (Figure 2). The mutation of V91 and E95 also caused significant losses of aripiprazole's affinity and a functional effect, consistent with the loss of SBP interactions. We propose that the interaction of the SP with the SBP promotes a higher intrinsic efficacy whereas the orientation of the SP toward TM3 appears to be associated with a lower efficacy but a higher binding affinity. The combination of the V91 2.61 A mutation with the $\mathrm{L} 41^{1.39} \mathrm{~A}$ mutation, which we postulate would further promote the orientation of the SP toward TM3 over the SBP pose, caused an even greater (44-fold) loss of efficacy. In our recent studies of extended 2,3-diCl-phenylpiperazine derivatives, we found that the structures of both the SP and the linker can modulate ligand efficacy. We proposed a mechanism whereby the interaction of the linker and SP with the SBP modulated the conformation of the PP in the OBS, leading to changes in ligand efficacy. ${ }^{18}$ The relationship between distinct binding orientations of a single ligand at a receptor and efficacy has been explored in studies of extended bitopic ligands that bind the muscarinic $\mathrm{M}_{2}$ acetylcholine receptor. ${ }^{34}$ In this study, it is proposed that such ligands can bind the receptor in two distinct orientations, one that occupies the OBS and one purely allosteric mode that does not. ${ }^{34}$ The relative propensity of such ligands to occupy the receptor in an orthosteric versus an allosteric orientation determined the intrinsic efficacy. In the study presented here, we find no evidence that aripiprazole can bind the $\mathrm{D}_{2} \mathrm{R}$ in a purely allosteric mode. Rather, we propose that the $\mathrm{PP}$ of aripiprazole occupies the OBS in a rather stable pose in both orientations of the ligand and that the direct interaction of the SP of aripiprazole with the SBP confers an increase in efficacy. We have also shown that the interaction of the $\mathrm{SP}$ of a $\mathrm{D}_{2} \mathrm{R}$ negative allosteric modulator with a similar SBP was required for allosteric pharmacology, whereas the PP of this ligand acted as a competitive antagonist. ${ }^{35}$ Together with the study presented here, this illustrates that the interaction of SP of extended ligands with the SBP of the $\mathrm{D}_{2} \mathrm{R}$ can confer 
changes in pharmacology relative to that which resulted from binding of the primary pharmacophore of each ligand in the orthosteric binding site.

Mutation of SBP residues also influenced the binding and functional affinity of small orthosteric agonists not expected to interact with the SBP. The effects of these mutants upon aripiprazole compared to their effects on the smaller agonists were, however, distinct. In the case of SBP mutations that affected the action of all three agonists $\left(\mathrm{V} 91^{2.61} \mathrm{~F}\right.$ and $\mathrm{L} 41^{1.39} \mathrm{~A} / \mathrm{V} 91^{2.61} \mathrm{~A}$ ), the effect on aripiprazole was much stronger. It should be noted, however, that while the $\mathrm{L} 41^{1.39} \mathrm{~A}$ mutation or the $\mathrm{L} 41^{1.39} \mathrm{~A} / \mathrm{V} 91^{2.61} \mathrm{~A}$ double mutation did not affect the efficacy of dopamine or ropinirole, each caused a decrease in the functional affinity of dopamine. The functional affinity presumably reflects the affinity of dopamine for the receptor when coupled to signaling effectors. ${ }^{36}$ In contrast, the binding affinity of dopamine, which was unchanged relative to that of WT, reflects the affinity of dopamine for the uncoupled state of the receptor. Dopamine cannot make direct contacts with this SBP residue when bound in the OBS. Thus, this mutation appears to modulate the affinity with which dopamine binds to a coupled receptor state but does not affect the efficiency with which it stimulates receptor-mediated $\mathrm{G}$ protein activation. In addition, the indirect effect of this mutation upon dopamine's functional affinity is distinct from the effect upon aripiprazole efficacy that we propose is caused by modulation of the interaction between the SP and the SBP. Nonetheless, our data indicate that residues within the SBP can influence the binding of even small agonists to the OBS. This effect is dependent upon the structure of the orthosteric agonist as the L41 ${ }^{1.39}$ A mutation had no effect on ropinirole. This is difficult to reconcile with a global effect of this mutation, such as the impairment of the transition to an active receptor state, as one would envisage that all agonists would be affected in a similar manner. Dopamine and ropinirole were shown to display distinct sensitivities to the mutation of OBS residues; for example, the S1975.46 A mutation ablated dopamine's functional activity but had no effect on ropinirole. Thus, they are likely to have distinct patterns of interaction with the OBS. The mutation of L $41^{1.39}$ may modulate the conformation of the OBS in a manner that affects the functional affinity of some but not all agonists and is dependent upon their structure and the residues they engage to exert their effect. Consistent with the idea of changes in the conformation of the SBP modulating the binding of agonists to the OBS, we have previously shown that a SP fragment of an extended $\mathrm{D}_{2} \mathrm{R}$ ligand acted as a negative allosteric modulator and that its binding was sensitive to SBP. ${ }^{37}$ Moreover, allosteric modulators of the muscarinic receptor interact with residues that align with those forming the $\mathrm{D}_{2} \mathrm{R}$ SBP. ${ }^{38,39}$ A SBP defined by residues of extracellular TM1, TM2, and TM7 has also been implicated in the agonist binding and/or activation of the chemokine CCR5, nicotinic acid (GPR109A), and angiotensin 1 receptors. 40-42 Thus, the SBP defined in this study is likely to be important for the modulation of agonist action in other GPCRs.

\section{The Biased Agonism of Aripiprazole Is Unchanged in OBS or SBP Mutants.}

Previously, we have shown that aripiprazole displays biased agonism toward inhibition of cAMP over phosphorylation of ERK1/2. ${ }^{43,44}$ In our pERK1/2 assay, aripiprazole displayed a maximal response of $29 \%$ of ropinirole at the $\mathrm{WT}_{2} \mathrm{R}$, corresponding to an efficacy of $0.39,12$-fold lower than that observed in the cAMP assay (Figure 5 and Supplementary 
Table 5). We quantified the biased agonism of dopamine and aripiprazole between inhibition of cAMP production and ERK1/2 phosphorylation using ropinirole as the reference agonist.

${ }^{21}$ Consistent with our previous results, aripiprazole was biased toward the inhibition of cAMP production over ERK1/2 phosphorylation whereas dopamine was not (Supplementary Table 6). ${ }^{43}$ None of the OBS or SBP mutations caused a significant change in this bias. Note, however, that the window in which the deleterious effects of a mutation can be detected is smaller in the pERK1/2 assay because of the lower efficacy of aripiprazole at the WT $D_{2} R$ as compared to that obtained in the cAMP assay. Accordingly, we were unable to quantify a change in bias for the mutations that abrogated aripiprazole action in the pERK1/2 assay but that also had a deleterious effect in the cAMP assay (for example, $\mathrm{L} 41^{1.39} \mathrm{~A}$ and $\mathrm{V} 91^{2.61} \mathrm{~A}$ ). While previous studies have shown that aripiprazole does not display bias between cAMP and $\beta$-arrestin recruitment, ${ }^{43,45}$ we were curious to see whether $\mathrm{L} 41^{1.39} \mathrm{~A}$ might change this. In a $\beta$-arrestin translocation assay that measures the movement of a $\beta$-arrestin-2-Venus to the cell surface, aripiprazole acted as a partial agonist at the WT D2R [Emax $=86 \%$ of maximal response of ropinirole (Figure 5 and Supplementary Table 7)]. Aripiprazole displayed a significant 6-fold decrease in efficacy in the $L 41^{1.39}$ A mutant as compared to that of WT. No bias between cAMP and $\beta$-arrestin- 2 translocation was observed for dopamine or aripiprazole relative to ropinirole at the WT or $\mathrm{L} 41^{1.39} \mathrm{~A}_{2} \mathrm{R}$ (Figure 5 and Supplementary Table 7).

\section{Conclusions.}

The weak intrinsic efficacy of $\mathrm{D}_{2} \mathrm{R}$ partial agonists such as aripiprazole is thought to determine both their antipsychotic effect and their low propensity to cause extrapyramidal side effects and hyperprolactinemia as compared to those of typical antipsychotics. Our results reveal the molecular interactions that are important for this intrinsic efficacy.

Aripiprazole's structure is typical of many $\mathrm{D}_{2}$-like DR subtype-selective ligands, namely a substituted piperazine PP and a lipophilic SP. ${ }^{7,17}$ Previous studies have revealed that the addition of a SP to a piperazine PP can confer gains in affinity and subtype selectivity through interaction with a SBP defined by the extracellular ends of TM1, TM2, and TM7. ${ }^{7-10,18,33,46,47}$ In this study, we find that the interaction of the quinalinone SP of aripiprazole with the SBP is a key determinant of the intrinsic efficacy of this drug. Addition of aripiprazole's SP to the 2,3-diCl-phenylpiperazine PP or a distinct 2methoxyphenylpiperazine PP fragment conferred gains in both affinity and efficacy. These data, combined with our previous study that found that the interaction of an SP with a distinct indole structure with the SBP caused a decrease in intrinsic efficacy, ${ }^{18}$ provide a means of designing D2R partial agonists with the desired intrinsic efficacy.

\section{METHODS}

\section{Materials.}

Aripiprazole was synthesized in house as previously described and shown to be $>98 \%$ pure.

${ }^{43}$ Ropinirole was purchased from BetaPharma Co. Ltd. (Wujiang, China) and was $>98 \%$ pure as described by the supplier. All novel compounds were synthesized as described in the Supporting Information. pcDNA31-His-CAMYEL was purchased from ATCC. Dulbecco's modified Eagle's medium (DMEM), hygromycin B, and FlpIn CHO cells were purchased 
from Invitrogen (Carlsbad, CA). Fetal bovine serum (FBS) was purchased from ThermoTrace (Melbourne, Australia). $\left[{ }^{3} \mathrm{H}\right]$ Spiperone, $\left[{ }^{3} \mathrm{H}\right]$ raclopride, Alpha-Screen reagents, Ultima gold scintillation cocktail, 384-well optiplates, and 384-well proxiplates were purchased from PerkinElmer (Boston, MA). All of the other reagents were purchased from Sigma-Aldrich (Castle Hill, Australia).

\section{Molecular Biology and Generation of Cell Lines.}

The molecular biology and generation of cell lines were performed as described previously. ${ }^{43}$ Full details are given in the Supporting Information. cDNA in pcDNA3.1+ encoding the short isoform of the wild-type human dopamine D2 receptor with an N-terminal SNAP tag was obtained from Cisbio (Bagnols-sur-Cèze, France).

\section{ELISA and Cell Signaling Assays.}

The ELISA protocol, ERK1/2 phosphorylation assay, cAMP Alpha-screen assay, and BRET assays measuring intracellular cAMP and $\beta$-arrestin- 2 recruitment to the plasma membrane were performed as described previously. ${ }^{43,48}$ Full details are given in the Supporting Information.

\section{Membrane Preparation and Radioligand Binding Assays.}

Radioligand binding assays were performed as described previously. ${ }^{43}$ Full details are given in the Supporting Information.

\section{Data Analysis.}

The results were analyzed using Prism 6.0 (GraphPad Software Inc., San Diego, CA). Full details of data analysis are given in the Supporting Information. All affinity $\left(\mathrm{p} K_{\mathrm{i}}, \mathrm{p} K_{\mathrm{D}}\right.$, or $\left.\mathrm{p} K_{\mathrm{A}}\right)$, potency $\left(\mathrm{pEC}_{50}\right)$, and transduction ratio $\left[\log \left(\tau / K_{\mathrm{A}}\right)\right]$ parameters were estimated as logarithms, where fold changes were calculated using the corresponding antilog values. We have previously demonstrated that the distribution of the antilog parameters does not conform to a normal (Gaussian) distribution whereas the logarithm is approximately Gaussian. Thus, because the application of $t$ tests and analyses of variance assume a Gaussian distribution, estimating the parameters as logarithms allows valid statistical comparison. All results are expressed as means \pm the standard deviation. We performed a Brown-Forsythe test (GraphPad Prism 6.0) to ensure ourselves of equal variance when such parameters are compared.

\section{Simulations.}

Full details of the protocol are provided in the Supporting Information.

\section{Supplementary Material}

Refer to Web version on PubMed Central for supplementary material.

\section{ACKNOWLEDGMENTS}

This research was supported by Project Grant 1049564 from the National Health and Medical Research Council (NHMRC) and the National Institute on Drug Abuse-Intramural Research Program (Z1A DA000606-03) (L.S.). 


\section{REFERENCES}

(1). Beaulieu J-M, and Gainetdinov RR (2011) The Physiology, Signaling, and Pharmacology of Dopamine Receptors. Pharmacol. Rev 63, 182-217. [PubMed: 21303898]

(2). Burris KD (2002) Aripiprazole, a Novel Antipsychotic, Is a High-Affinity Partial Agonist at Human Dopamine D2 Receptors. J. Pharmacol. Exp. Ther 302, 381-389. [PubMed: 12065741]

(3). Oshiro Y, Sato S, Kurahashi N, Tanaka T, Kikuchi T, Tottori K, Uwahodo Y, and Nishi T. (1998) Novel antipsychotic agents with dopamine autoreceptor agonist properties: synthesis and pharmacology of 7-[4-(4-phenyl-1-piperazinyl)butoxy]-3,4-dihydro-2(1H)-quinolinone derivatives. J. Med. Chem 41, 658-667. [PubMed: 9513593]

(4). Kiss B, Horvath A, Nemethy Z, Schmidt E, Laszlovszky I, Bugovics G, Fazekas K, Hornok K, Orosz S, Gyertyan I, Agai-Csongor E, Domany G, Tihanyi K, Adham N, and Szombathelyi Z. (2010) Cariprazine (RGH-188), a Dopamine D3 Receptor-Preferring, D3/D2 Dopamine Receptor Antagonist-Partial Agonist-Antipsychotic Candidate: In Vitro and Neurochemical Profile. J. Pharmacol. Exp. Ther 333, 328-340. [PubMed: 20093397]

(5). Lieberman JA (2004) Dopamine Partial Agonists: A New Class of Antipsychotic. CNS Drugs 18, 251-267. [PubMed: 15015905]

(6). Natesan S, Reckless GE, Barlow KBL, Nobrega JN, and Kapur S. (2011) Partial agonists in schizophrenia-why some work and others do not: insights from preclinical animal models. Int. J. Neuropsychopharmacol 14, 1165-1178. [PubMed: 21087552]

(7). Chien EYT, Liu W, Zhao Q, Katritch V, Won Han G, Hanson MA, Shi L, Newman AH, Javitch JA, Cherezov V, and Stevens RC (2010) Structure of the Human Dopamine D3 Receptor in Complex with a D2/D3 Selective Antagonist. Science 330, 1091-1095. [PubMed: 21097933]

(8). Shi L, and Javitch JA (2002) The binding site of aminergic G protein-coupled receptors: the transmembrane segments and second extracellular loop. Annu. Rev. Pharmacol. Toxicol 42, 437467. [PubMed: 11807179]

(9). Wang S, Wacker D, Levit A, Che T, Betz RM, McCorvy JD, Venkatakrishnan AJ, Huang X-P, Dror RO, Shoichet BK, and Roth BL (2017) D4 dopamine receptor high-resolution structures enable the discovery of selective agonists. Science 358, 381-386. [PubMed: 29051383]

(10). Wang S, Che T, Levit A, Shoichet BK, Wacker D, and Roth BL (2018) Structure of the D2 dopamine receptor bound to the atypical antipsychotic drug risperidone. Nature 555, 269-273. [PubMed: 29466326]

(11). Venkatakrishnan AJ, Deupi X, Lebon G, Tate CG, Schertler GF, and Babu MM (2013) Molecular signatures of G-protein-coupled receptors. Nature 494, 185-194. [PubMed: 23407534]

(12). Deupi X, and Standfuss J. (2011) Structural insights into agonist-induced activation of G-proteincoupled receptors. Curr. Opin.Struct. Biol 21, 541-551. [PubMed: 21723721]

(13). Ballesteros JA, and Weinstein H. (1995) Methods in Neuroscience, pp 366-428, Elsevier.

(14). Huang W, Manglik A, Venkatakrishnan AJ, Laeremans T, Feinberg EN, Sanborn AL, Kato HE, Livingston KE, Thorsen TS, Kling RC, Granier S, Gmeiner P, Husbands SM, Traynor JR, Weis WI, Steyaert J, Dror RO, and Kobilka BK (2015) Structural insights into $\mu$-opioid receptor activation. Nature 524, 315-321. [PubMed: 26245379]

(15). Latorraca NR, Venkatakrishnan AJ, and Dror RO (2017) GPCR Dynamics: Structures in Motion. Chem. Rev 117, 139-155. [PubMed: 27622975]

(16). Dror RO, Arlow DH, Maragakis P, Mildorf TJ, Pan AC, Xu H, Borhani DW, and Shaw DE (2011) Activation mechanism of the $\beta 2$-adrenergic receptor. Proc. Natl. Acad. Sci. U. S. A 108, 18684-18689. [PubMed: 22031696]

(17). Löber S, Hübner H, Tschammer N, and Gmeiner P. (2011) Recent advances in the search for D3and D4-selective drugs: probes, models and candidates. Trends Pharmacol. Sci 32, 148-157. [PubMed: 21232805]

(18). Newman AH, Beuming T, Banala AK, Donthamsetti P, Pongetti K, LaBounty A, Levy B, Cao J, Michino M, Luedtke RR, Javitch JA, and Shi L. (2012) Molecular determinants of selectivity and efficacy at the dopamine D3 receptor. J. Med. Chem 55, 6689-6699. [PubMed: 22632094]

(19). Michino M, Boateng CA, Donthamsetti P, Yano H, Bakare OM, Bonifazi A, Ellenberger MP, Keck TM, Kumar V, Zhu C, Verma R, Deschamps JR, Javitch JA, Newman AH, and Shi L. 
(2017) Toward Understanding the Structural Basis of Partial Agonism at the Dopamine D3 Receptor. J. Med. Chem 60, 580-593. [PubMed: 27983845]

(20). Tadori Y, Miwa T, Tottori K, Burris KD, Stark A, Mori T, and Kikuchi T. (2005) Aripiprazole's low intrinsic activities at human dopamine $\mathrm{D} 2 \mathrm{~L}$ and $\mathrm{D} 2 \mathrm{~S}$ receptors render it a unique antipsychotic. Eur. J. Pharmacol 515, 10-19. [PubMed: 15894311]

(21). Kenakin T, Watson C, Muniz-Medina V, Christopoulos A, and Novick S. (2012) A Simple Method for Quantifying Functional Selectivity and Agonist Bias. ACS Chem. Neurosci 3, 193 203. [PubMed: 22860188]

(22). Mansour A, Meng F, Meador-Woodruff JH, Taylor LP, Civelli O, and Akil H. (1992) Sitedirected mutagenesis of the human dopamine D2 receptor. Eur. J. Pharmacol., Mol. Pharmacol. Sect 227, 205-214.

(23). Chemel BR, Bonner LA, Watts VJ, and Nichols DE (2012) Ligand-Specific Roles for Transmembrane 5 Serine Residues in the Binding and Efficacy of Dopamine D1 Receptor Catechol Agonists. Mol. Pharmacol 81, 729-738. [PubMed: 22334593]

(24). Woodward R, Coley C, Daniell S, Naylor LH, and Strange PG (1996) Investigation of the role of conserved serine residues in the long form of the rat D2 dopamine receptor using site-directed mutagenesis. J. Neurochem 66, 394-402. [PubMed: 8522980]

(25). Sartania N, and Strange PG (1999) Role of conserved serine residues in the interaction of agonists with D3 dopamine receptors. J. Neurochem 72, 2621-2624. [PubMed: 10349875]

(26). Wilcox RE, Huang WH, Brusniak MY, Wilcox DM, Pearlman RS, Teeter MM, DuRand CJ, Wiens BL, and Neve KA (2000) CoMFA-based prediction of agonist affinities at recombinant wild type versus serine to alanine point mutated D2 dopamine receptors. J. Med. Chem 43, 30053019. [PubMed: 10956209]

(27). Fowler JC, Bhattacharya S, Urban JD, Vaidehi N, and Mailman RB (2012) Receptor Conformations Involved in Dopamine D2L Receptor Functional Selectivity Induced by Selected Transmembrane-5 Serine Mutations. Mol. Pharmacol 81, 820-831. [PubMed: 22416052]

(28). Shi L, and Javitch JA (2004) The second extracellular loop of the dopamine D2 receptor lines the binding-site crevice. Proc. Natl. Acad. Sci. U. S. A 101, 440-445. [PubMed: 14704269]

(29). Tschammer N, Bollinger S, Kenakin T, and Gmeiner P. (2011) Histidine 6.55 Is a Major Determinant of Ligand-Biased Signaling in Dopamine D2L Receptor. Mol. Pharmaco.1 79, 575585.

(30). Javitch J, Ballesteros J, Weinstein H, and Chen J. (1998) A cluster of aromatic residues in the sixth membrane-spanning segment of the dopamine D2 receptor is accessible in the binding-site crevice. Biochemistry 37, 998-1006. [PubMed: 9454590]

(31). Wacker D, Wang C, Katritch V, Han GW, Huang X-P, Vardy E, McCorvy JD, Jiang Y, Chu M, Siu FY, Liu W, Xu HE, Cherezov V, Roth BL, and Stevens RC (2013) Structural features for functional selectivity at serotonin receptors. Science 340, 615-619. [PubMed: 23519215]

(32). Zou M-F, Keck TM, Kumar V, Donthamsetti P, Michino M, Burzynski C, Schweppe C, Bonifazi A, Free RB, Sibley DR, Janowsky A, Shi L, Javitch JA, and Newman AH (2016) Novel Analogues of (R)-5-(Methylamino)-5,6-dihydro-4H-imidazo[4,5,1-ij]quinolin-2(1H)-one (Sumanirole) Provide Clues to Dopamine D2/D3 Receptor Agonist Selectivity. J. Med. Chem 59, 2973-2988. [PubMed: 27035329]

(33). Michino M, Beuming T, Donthamsetti P, Newman AH, Javitch JA, and Shi L. (2015) What can crystal structures of aminergic receptors tell us about designing subtype-selective ligands? Pharmacol. Rev 67, 198-213. [PubMed: 25527701]

(34). Bock A, Chirinda B, Krebs F, Messerer R, Bätz J, Muth M, Dallanoce C, Klingenthal D, Tränkle C, Hoffmann C, De Amici M, Holzgrabe U, Kostenis E, and Mohr K. (2014) Dynamic ligand binding dictates partial agonism at a $\mathrm{G}$ protein-coupled receptor. Nat. Chem. Biol 10, 18-20. [PubMed: 24212135]

(35). Lane JR, Donthamsetti P, Shonberg J, Draper-Joyce CJ, Dentry S, Michino M, Shi L, López L, Scammells PJ, Capuano B, Sexton PM, Javitch JA, and Christopoulos A. (2014) A new mechanism of allostery in a $\mathrm{G}$ protein-coupled receptor dimer. Nat. Chem. Biol 10, 745-752. [PubMed: 25108820] 
(36). Kenakin T. (2014) What is pharmacological "affinity?" Relevance to biased agonism and antagonism. Trends Pharmacol. Sci 35, 434-441. [PubMed: 25042457]

(37). Mistry SN, Shonberg J, Draper-Joyce CJ, Klein Herenbrink C, Michino M, Shi L, Christopoulos A, Capuano B, Scammells PJ, and Lane JR (2015) Discovery of a Novel Class of Negative Allosteric Modulator of the Dopamine D2 Receptor Through Fragmentation of a Bitopic Ligand. J. Med. Chem 58, 6819-6843. [PubMed: 26258690]

(38). Dror RO, Green HF, Valant C, Borhani DW, Valcourt JR, Pan AC, Arlow DH, Canals M, Lane JR, Rahmani R, Baell JB, Sexton PM, Christopoulos A, and Shaw DE (2013) Structural basis for modulation of a G-protein-coupled receptor by allosteric drugs. Nature 503, 295-299. [PubMed: 24121438]

(39). Abdul-Ridha A, Lane JR, Mistry SN, Lopez L, Sexton PM, Scammells PJ, Christopoulos A, and Canals M. (2014) Mechanistic Insights into Allosteric Structure-Function Relationships at the M1Muscarinic Acetylcholine Receptor. J. Biol. Chem 289, 33701-33711. [PubMed: 25326383]

(40). Rosenkilde MM, Benned-Jensen T, Frimurer TM, and Schwartz TW (2010) The minor binding pocket: a major player in 7TM receptor activation. Trends Pharmacol. Sci 31, 567-574. [PubMed: 20870300]

(41). Govaerts C, Blanpain C, Deupi X, Ballet S, Ballesteros JA, Wodak SJ, Vassart G, Pardo L, and Parmentier M. (2001) The TXP motif in the second transmembrane helix of CCR5. J. Biol. Chem 276, 13217-13225. [PubMed: 11278962]

(42). Reis RI, Santos EL, Pesquero JB, Oliveira L, Schanstra JP, Bascands J-L, Pecher C, Paiva ACM, and Costa-Neto CM (2007) Participation of transmembrane proline 82 in angiotensin II AT1 receptor signal transduction. Regul. Pept 140, 32-36. [PubMed: 17239455]

(43). Klein Herenbrink C, Sykes DA, Donthamsetti P, Canals M, Coudrat T, Shonberg J, Scammells PJ, Capuano B, Sexton PM, Charlton SJ, Javitch JA, Christopoulos A, and Lane JR (2016) The role of kinetic context in apparent biased agonism at GPCRs. Nat. Commun 7, 10842. [PubMed: 26905976]

(44). Szabo M, Klein Herenbrink C, Christopoulos A, Lane JR, and Capuano B. (2014) StructureActivity Relationships of Privileged Structures Lead to the Discovery of Novel Biased Ligands at the Dopamine D 2Receptor. J. Med. Chem 57, 4924-4939. [PubMed: 24827597]

(45). Allen JA, Yost JM, Setola V, Chen X, Sassano MF, Chen M, Peterson S, Yadav PN, Huang X-P, Feng B, Jensen NH, Che X, Bai X, Frye SV, Wetsel WC, Caron MG, Javitch JA, Roth BL, and Jin J. (2011) Discovery of $\beta$-arrestin-biased dopamine D2 ligands for probing signal transduction pathways essential for antipsychotic efficacy. Proc. Natl. Acad. Sci. U. S. A 108, 18488-18493. [PubMed: 22025698]

(46). Simpson MM, Ballesteros JA, Chiappa V, Chen J, Suehiro M, Hartman DS, Godel T, Snyder LA, Sakmar TP, and Javitch JA (1999) Dopamine D4/D2 receptor selectivity is determined by A divergent aromatic microdomain contained within the second, third, and seventh membranespanning segments. Mol. Pharmacol 56, 1116-1126. [PubMed: 10570038]

(47). Michino M, Donthamsetti P, Beuming T, Banala A, Duan L, Roux T, Han Y, Trinquet E, Newman AH, Javitch JA, and Shi L. (2013) A single glycine in extracellular loop 1 is the critical determinant for pharmacological specificity of dopamine $\mathrm{d} 2$ and $\mathrm{d} 3$ receptors. Mol. Pharmacol 84, 854-864. [PubMed: 24061855]

(48). Donthamsetti P, Quejada JR, Javitch JA, Gurevich VV, and Lambert NA (2015) Using Bioluminescence Resonance Energy Transfer (BRET) to Characterize Agonist-Induced Arrestin Recruitment to Modified and Unmodified G Protein-Coupled Receptors. Curr. Protoc. Pharmacol 70, 2.14.1-2.14.14. [PubMed: 26331887] 
A

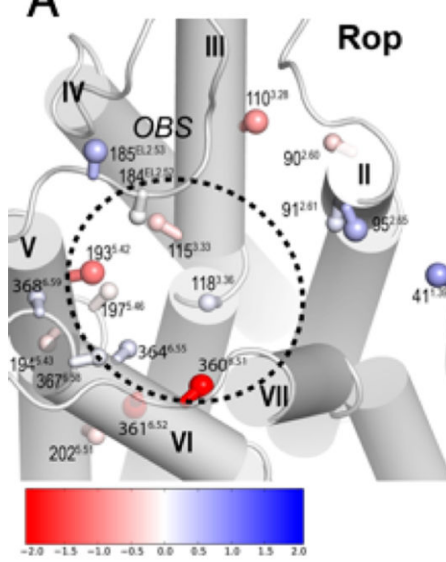

D

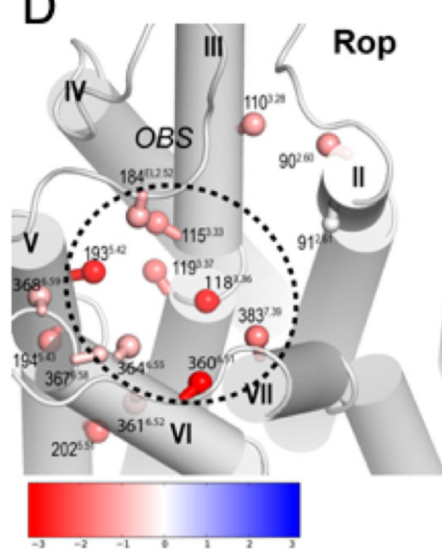

G

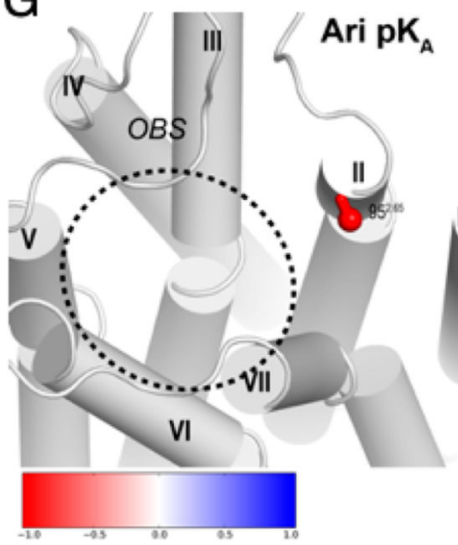

B

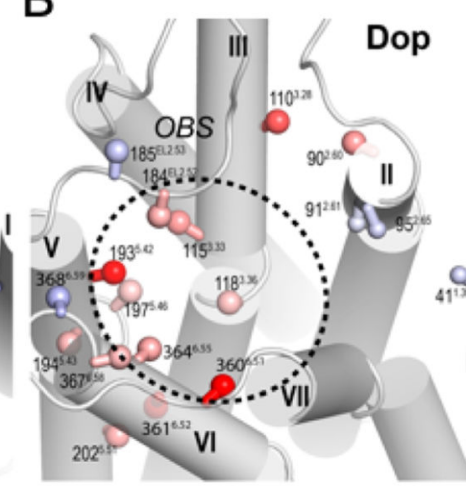

C

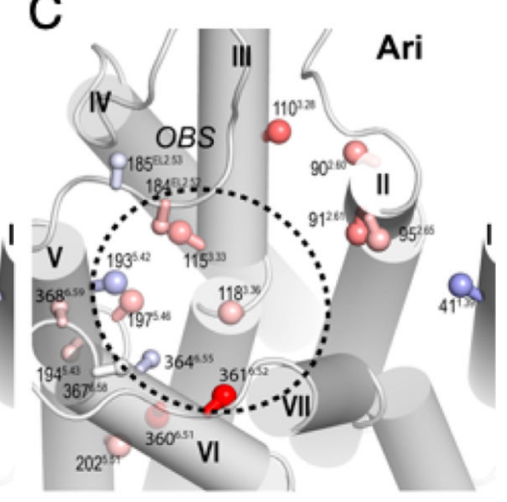

E

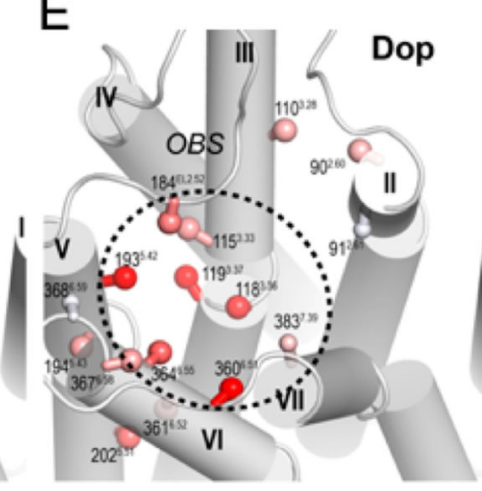

F

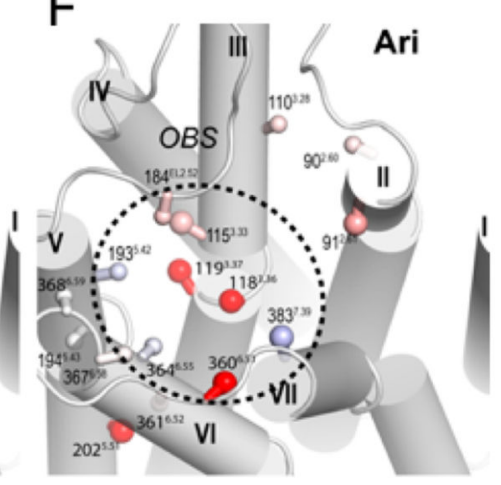

$\mathrm{H}$

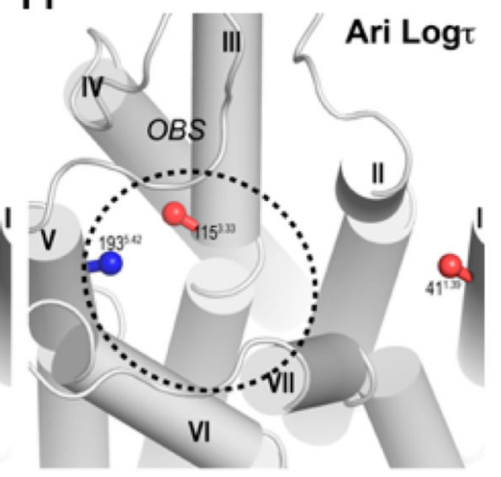

Figure 1.

Mutations of residues within the OBS and SBP have distinct effects on the affinity and efficacy of aripiprazole as compared to those of dopamine and ropinirole. WT and mutant $\mathrm{D}_{2}$ Rs were stably expressed in FlpIN CHO cells. The change in affinity $\left(\mathrm{p} K_{\mathrm{i}}\right)$ of $(\mathrm{A})$ ropinirole, (B) dopamine, and (C) aripiprazole for each mutant was determined in competition binding experiments. The ability to increase the concentration of each agonist to activate the WT or mutant $\mathrm{D}_{2}$ Rs was determined in an assay measuring the inhibition of cAMP production. These data were fit to an operational model of agonism, and changes in 
the transduction coefficient ( $\tau / K_{\mathrm{A}}$ ) were determined for (D) ropinirole, (E) dopamine, and $(\mathrm{F})$ aripiprazole for each mutant. Changes in $(\mathrm{G})$ functional affinity $\left(\mathrm{p} K_{\mathrm{A}}\right)$ and $(\mathrm{H})$ efficacy $(\tau)$ were also determined for aripiprazole. Mutations that cause significant increases (oneway analysis of variance with Dunnett's post hoc test; $p<0.05$; blue) or decreases (red) for each parameter for the mutant receptor as compared to that of the WT are highlighted on a homology model of the $\mathrm{D}_{2} \mathrm{R}$. 


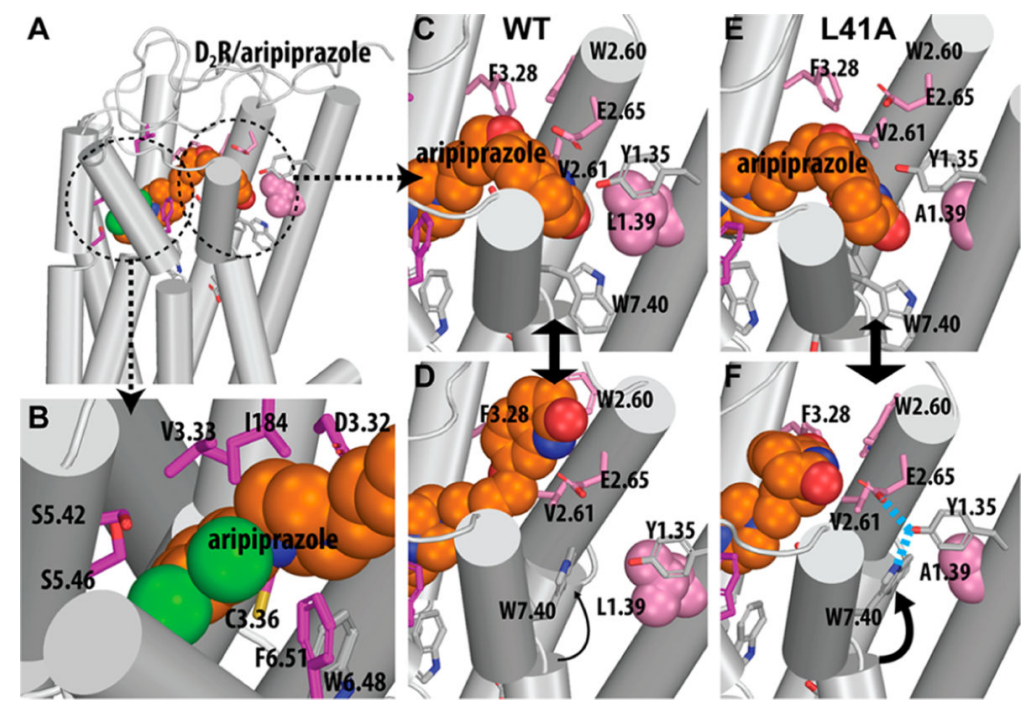

Figure 2.

Molecular modeling and ligand docking experiments reveal that aripiprazole adopts an extended orthosteric pose at the $\mathrm{D}_{2} \mathrm{R}$. (A) Molecular modeling and docking experiments using a homology model of the $\mathrm{D}_{2} \mathrm{R}$ followed by MD simulations reveal that aripiprazole adopts an extended orthosteric pose within the $\mathrm{D}_{2} \mathrm{R}$ and interacts with residues within the OBS and SBP. (B) Within the OBS, the 2,3-diCl-phenylpiperazine PP of aripiprazole adopts a pose parallel to the membrane oriented toward TM5. Within the SBP, the 1,2,3,4tetrahydroquinolin-2-one "tail" moiety and the flexible butoxy linker adopt two distinct poses depending on the orientation of $\operatorname{Trp} 3844^{7,40}$ (C) When this residue faces lipids, the quinalinone ring occupies a cavity within the SBP contacting residues from TM1, TM2, and TM7. (D) When Trp384 7.40 rotates inward, the quinalinone ring can no longer occupy the SBP but instead tilts toward TM3 and ECL2. (E and F) The L41 ${ }^{1.39}$ A mutation increases the propensity for $\operatorname{Trp} 384^{7.40}$ to rotate inward, allowing $\operatorname{Trp} 384^{7.40}$, Tyr $37^{1.35}$, and Glu95 2.65 to interact. 
A DCPP

1<smiles>Clc1cccc(N2CCNCC2)c1Cl</smiles>

2<smiles>CCCN1CCN(c2cccc(Cl)c2Cl)CC1</smiles>

3<smiles>CCCCN1CCN(c2cccc(Cl)c2Cl)CC1</smiles>

4<smiles>COCCCCN1CCN(c2cccc(Cl)c2Cl)CC1</smiles><smiles>O=C1CCc2ccc(OCCCCN3CCN(c4cccc(Cl)c4Cl)CC3)cc2N1</smiles>

C

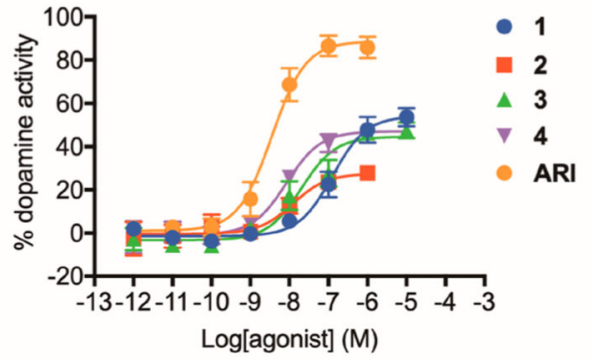

E
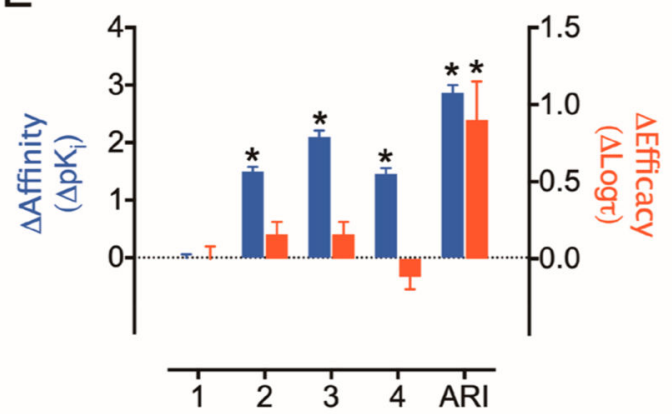

B 2MEOPP

11<smiles>COc1ccccc1N1CCNCC1</smiles>

12

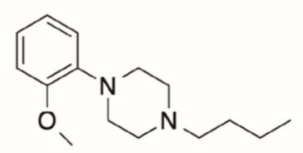

13
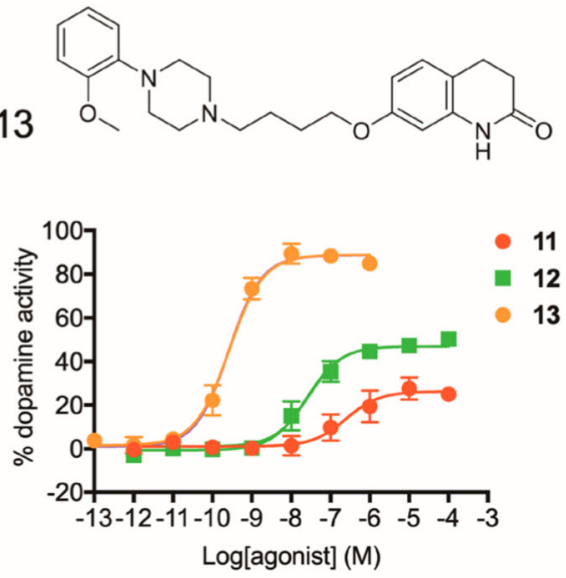

F

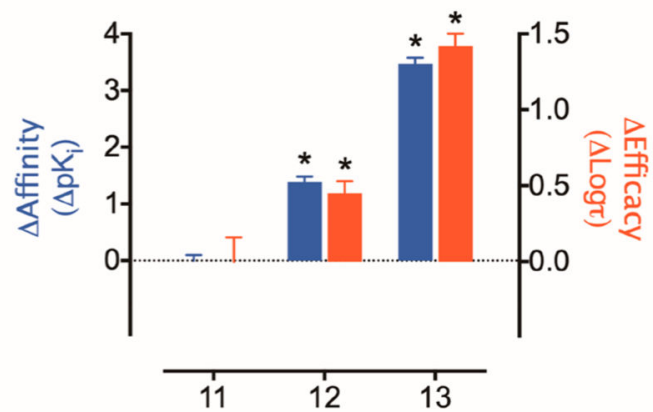

Figure 3.

7-Butoxy-1,2,3,4-tetrahydroquinolin-2-one substitution of a phenylpiperazine core confers an increase in efficacy and affinity. Two series of substituted phenylpiperazine fragments and extended compounds were synthesized, (A) one that incorporates the 2,3dichloropheylpiperazine (DCPP) core that includes aripiprazole and (B) one that incorporates the 2-methoxyphenylpiperazine core (2MeOPP). The ability of increasing concentrations of each compound in $(\mathrm{C}$ and $\mathrm{E})$ the DCPP series or ( $\mathrm{D}$ and $\mathrm{F}$ ) the $2 \mathrm{MeOPP}$ series to activate the $\mathrm{WT}_{2 S}$ Rs was determined through an assay measuring the inhibition 
of forskolin-stimulated cAMP production using a BRET biosensor. (E and F) These data were fit to an operational model of agonism, and changes in functional affinity or efficacy were determined as compared to the that of phenylpiperazine core of each series. An asterisk indicates a significant change in the parameter as compared to that of the core of each series (one-way analysis of variance with Dunnett's post hoc test; $p<0.05$ ). 
A

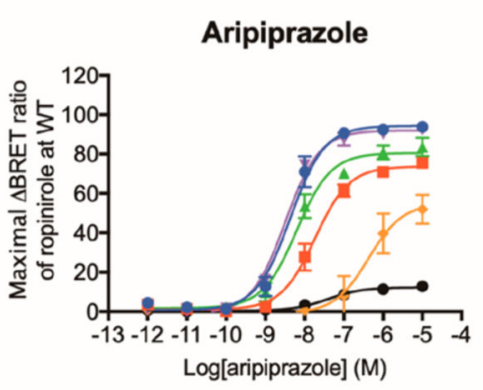

D

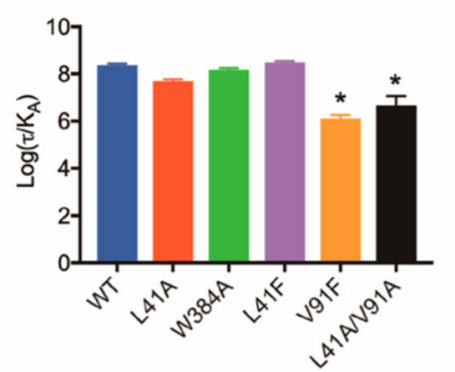

G

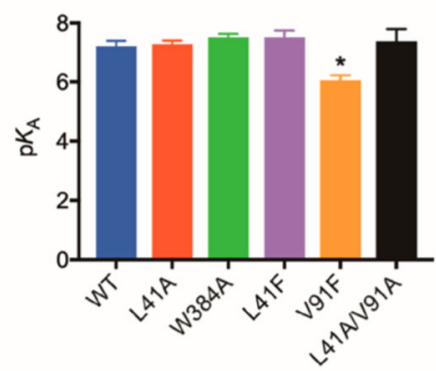

J

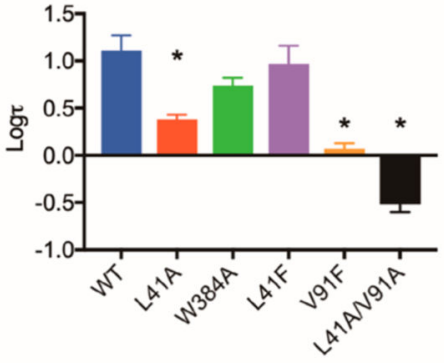

WT
B

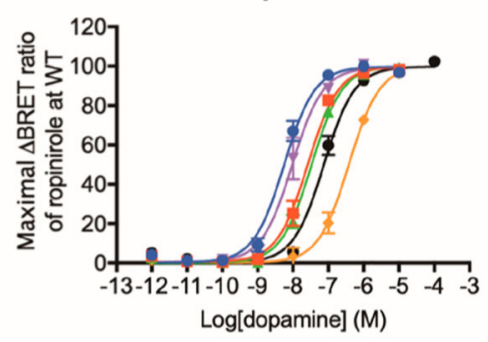

E

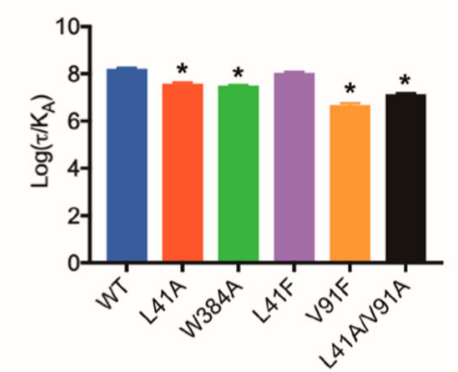

H

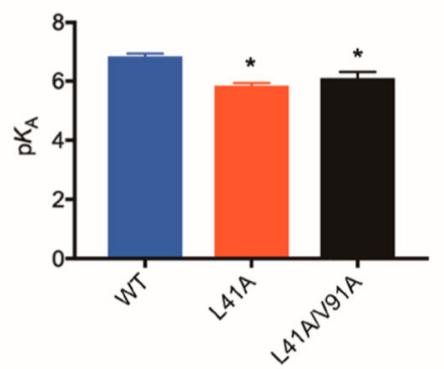

K

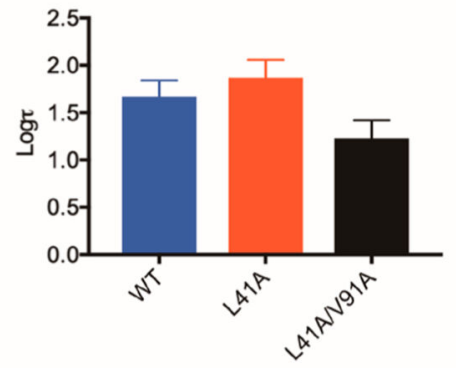

W384A
C

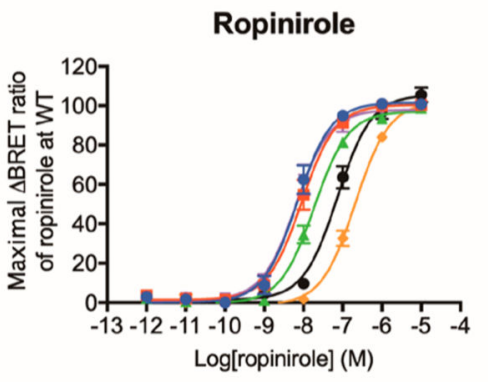

F
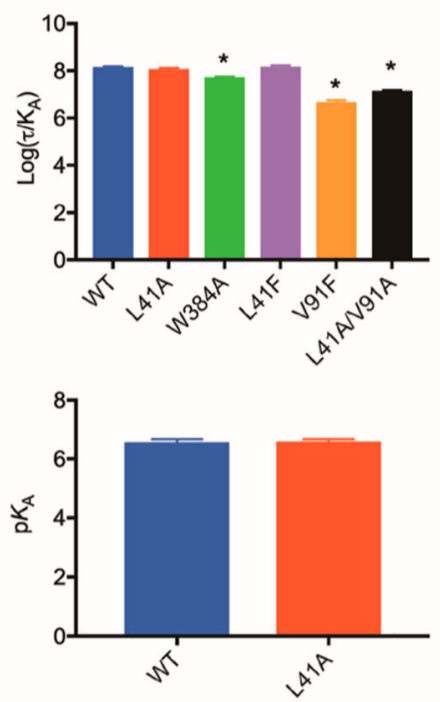

L

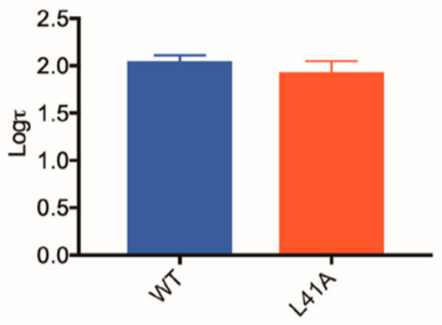

V91F

Figure 4.

Mutation of SBP residues decreases the efficacy of aripiprazole but not that of dopamine.

The ability of increasing concentrations of (A) aripiprazole, (B) dopamine, or (C) ropinirole to activate the WT or mutant $\left(\mathrm{L} 41^{1.39} \mathrm{~A}, \mathrm{~W} 3844^{7.40} \mathrm{~A}, \mathrm{~L} 41 \mathrm{~F}, \mathrm{~V} 91 \mathrm{~F}\right.$, and $\left.\mathrm{L} 41^{1.39} \mathrm{~A} / \mathrm{V} 91^{2.61} \mathrm{~A}\right)$ SNAP-tagged $\mathrm{D}_{2 S}$ Rs was determined in a BRET assay measuring the inhibition of forskolinstimulated cAMP production. These data were fit to an operational model of agonism and estimates of the (D-F) transduction coefficients and $(\mathrm{G}-\mathrm{I})$ functional affinities and $(\mathrm{J}-\mathrm{L})$ efficacies at the WT and mutant receptors. An asterisk indicates a significant change in the parameter for each agonist relative to WT (one-way analysis of variance with Dunnet's post hoc test; $p<0.05)$. 


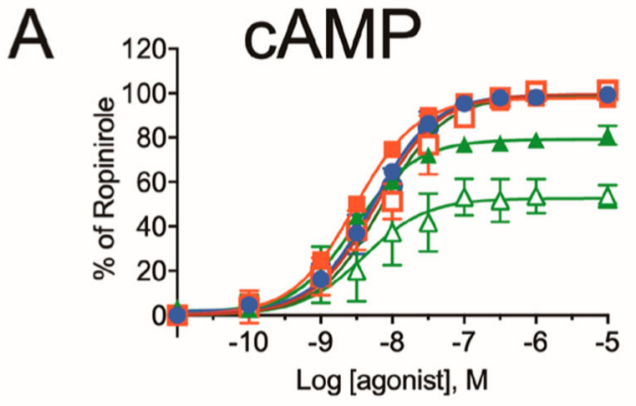

C

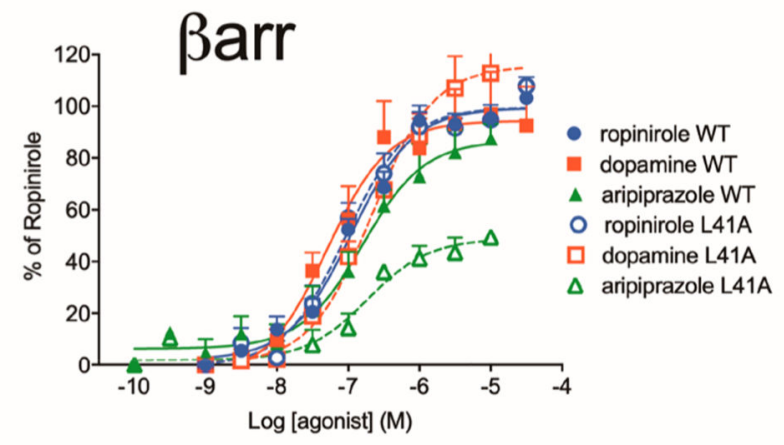

\section{B}

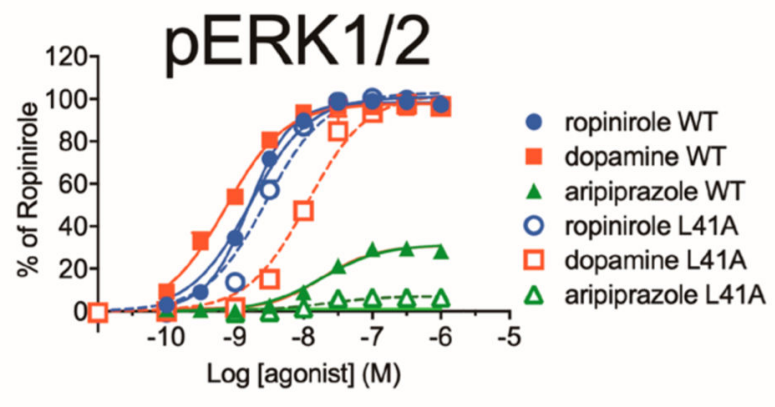

D

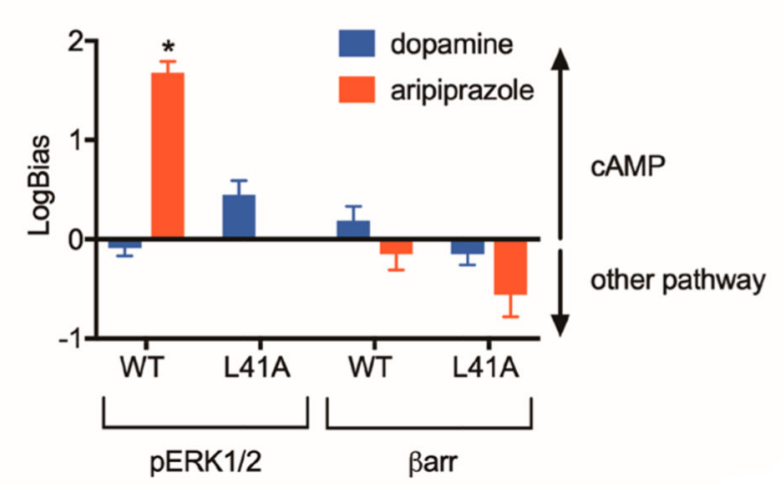

Figure 5.

Mutation $\mathrm{L} 41^{1.39} \mathrm{~A}$ decreases the intrinsic efficacy of aripiprazole at multiple signaling pathways. The ability of increasing concentrations of each agonist to activate the WT or L $41^{1.39} \mathrm{~A} \mathrm{D}_{2 \mathrm{~S}} \mathrm{Rs}$ was determined through an Alpha-screen assay measuring the inhibition of (A) forskolin stimulated cAMP production, (B) ERK1/2 phosphorylation, and (C) $\beta$-arrestin translocation. (D) These data were fit to an operational model of agonism, and bias factors between each pathway were determined for dopamine and aripiprazole relative to ropinirole. An asterisk indicates significant bias toward one pathway (two-tailed, unpaired Student's $t$ test; $p<0.05)$. 


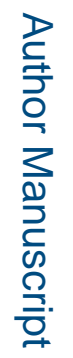

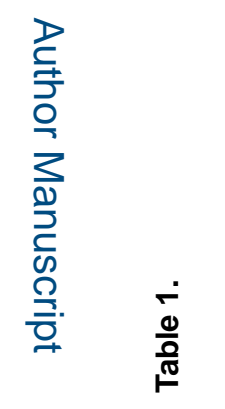

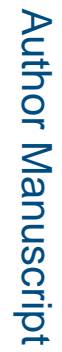

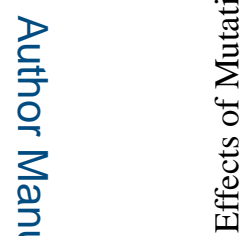

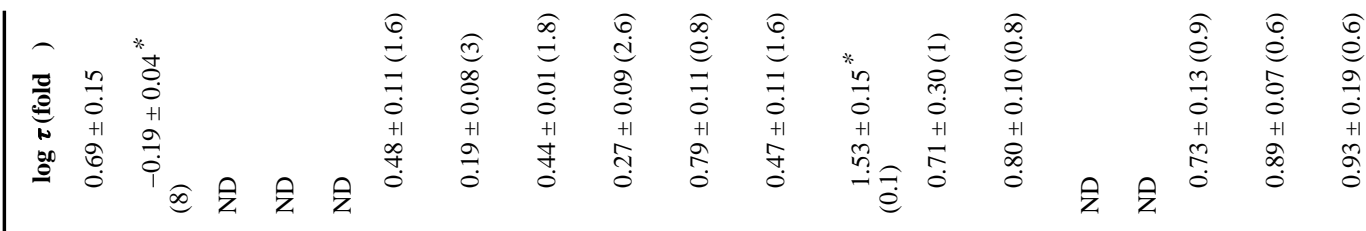

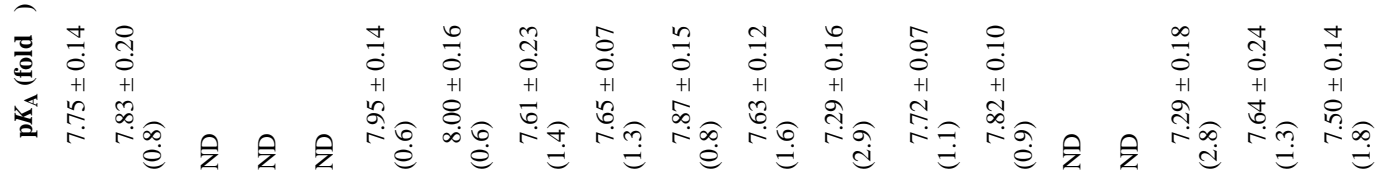

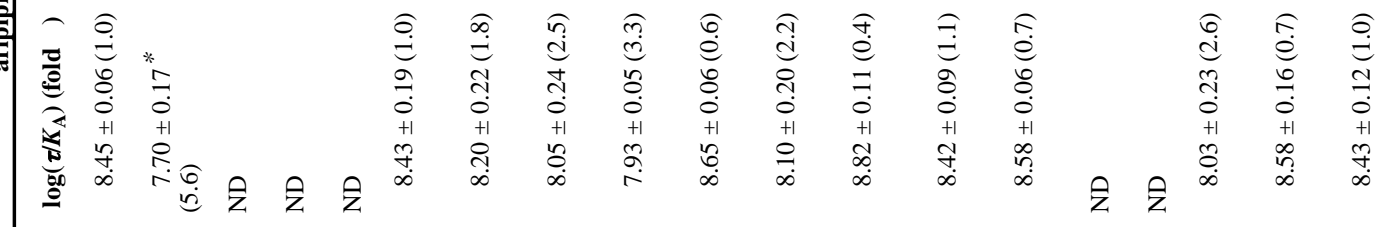

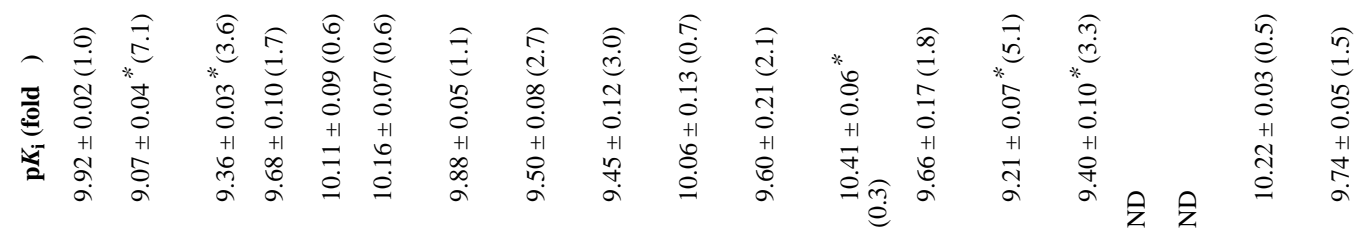

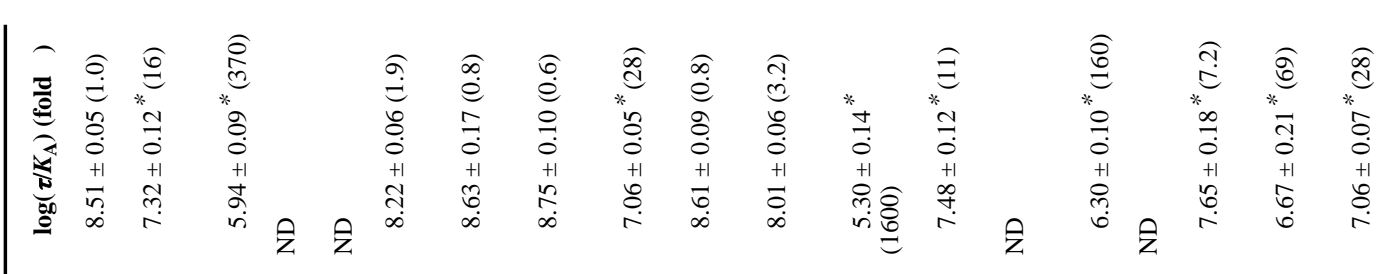

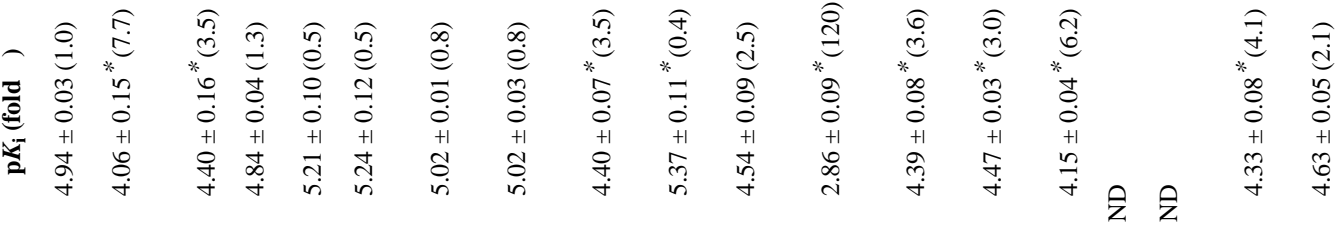

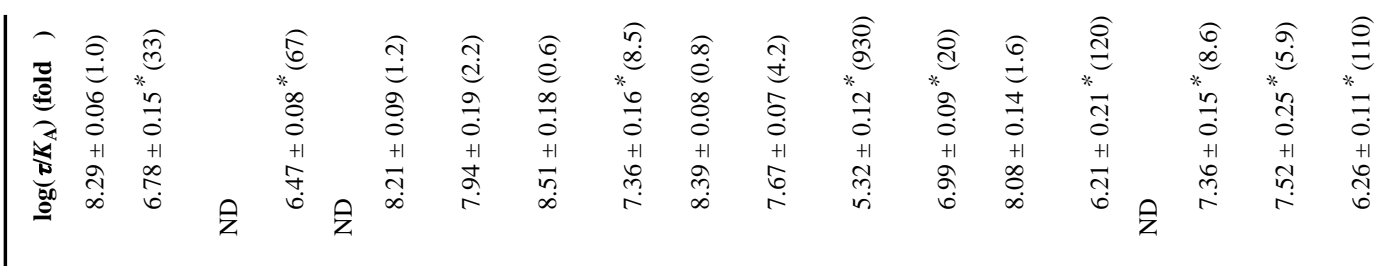




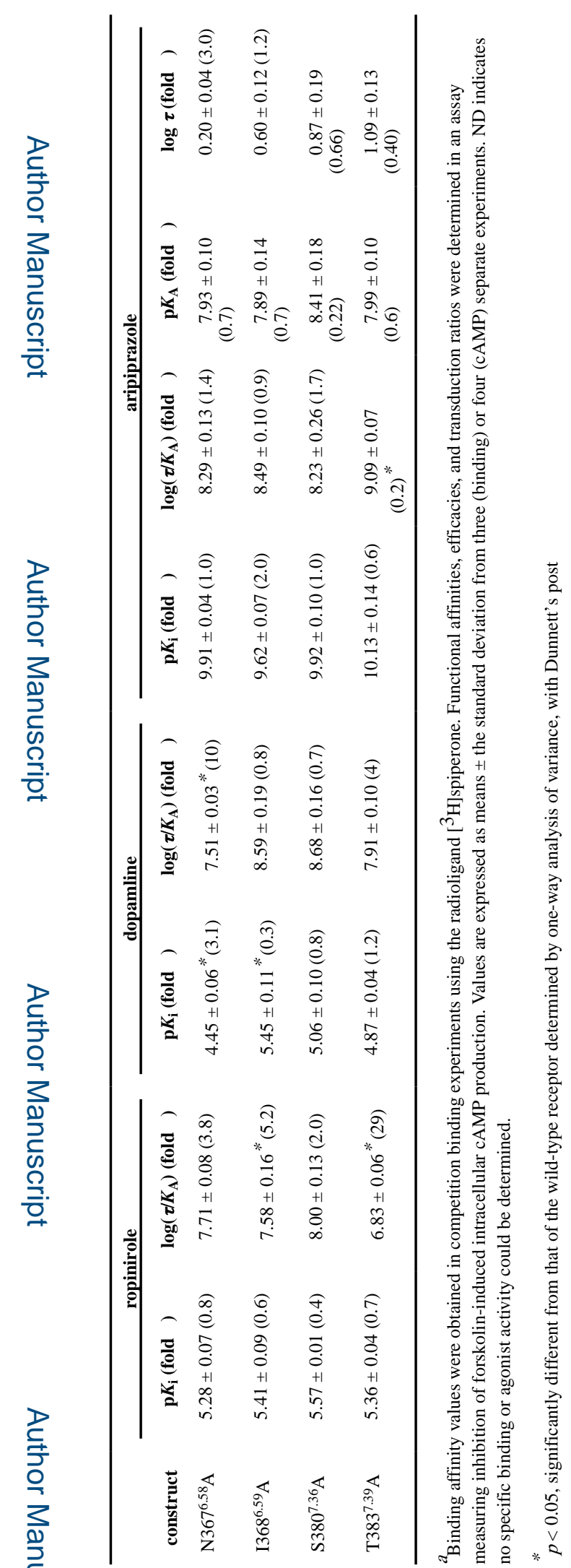

ACS Chem Biol. Author manuscript; available in PMC 2020 July 16. 


\section{로을}

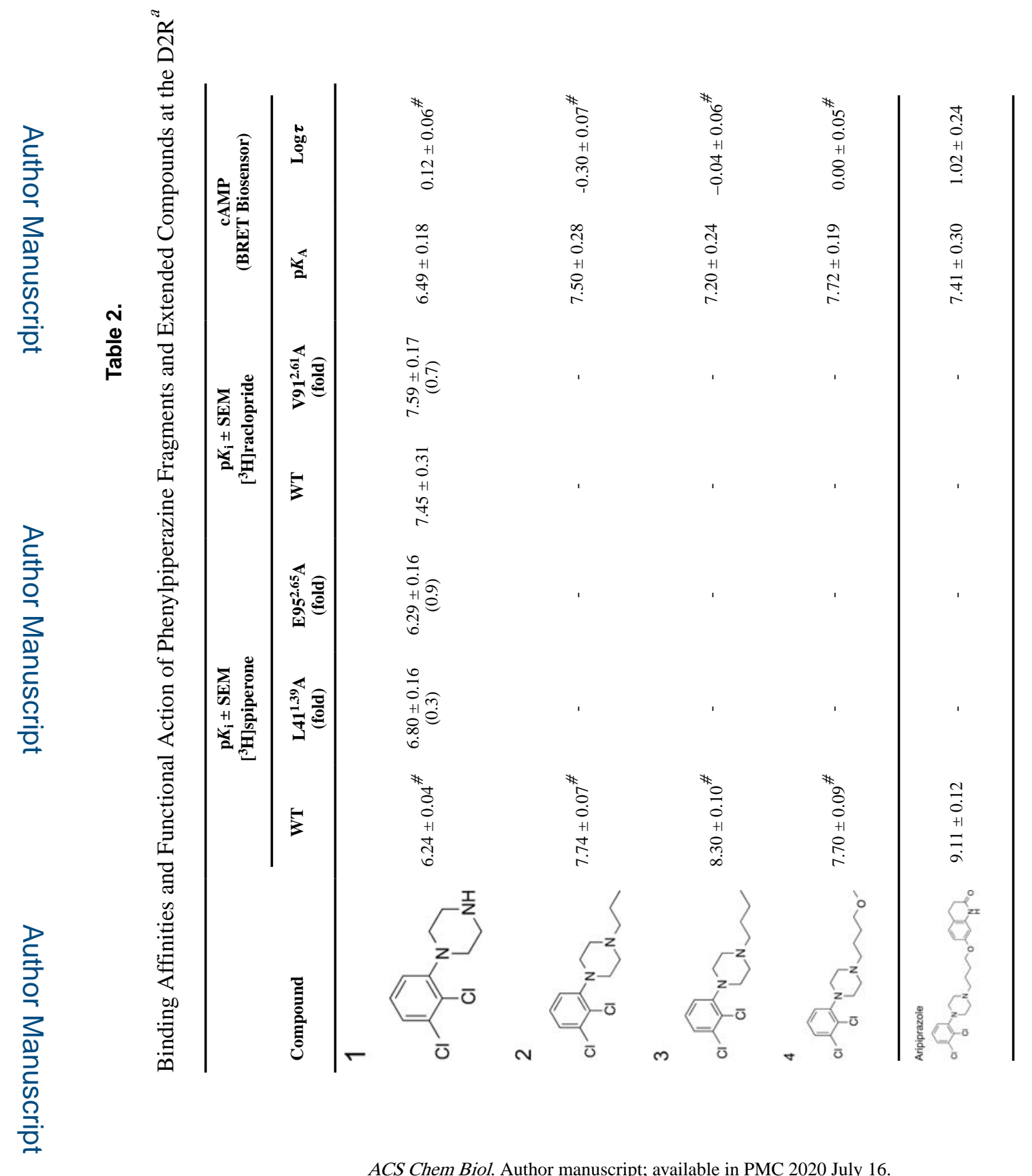




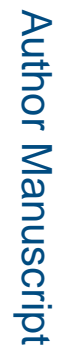
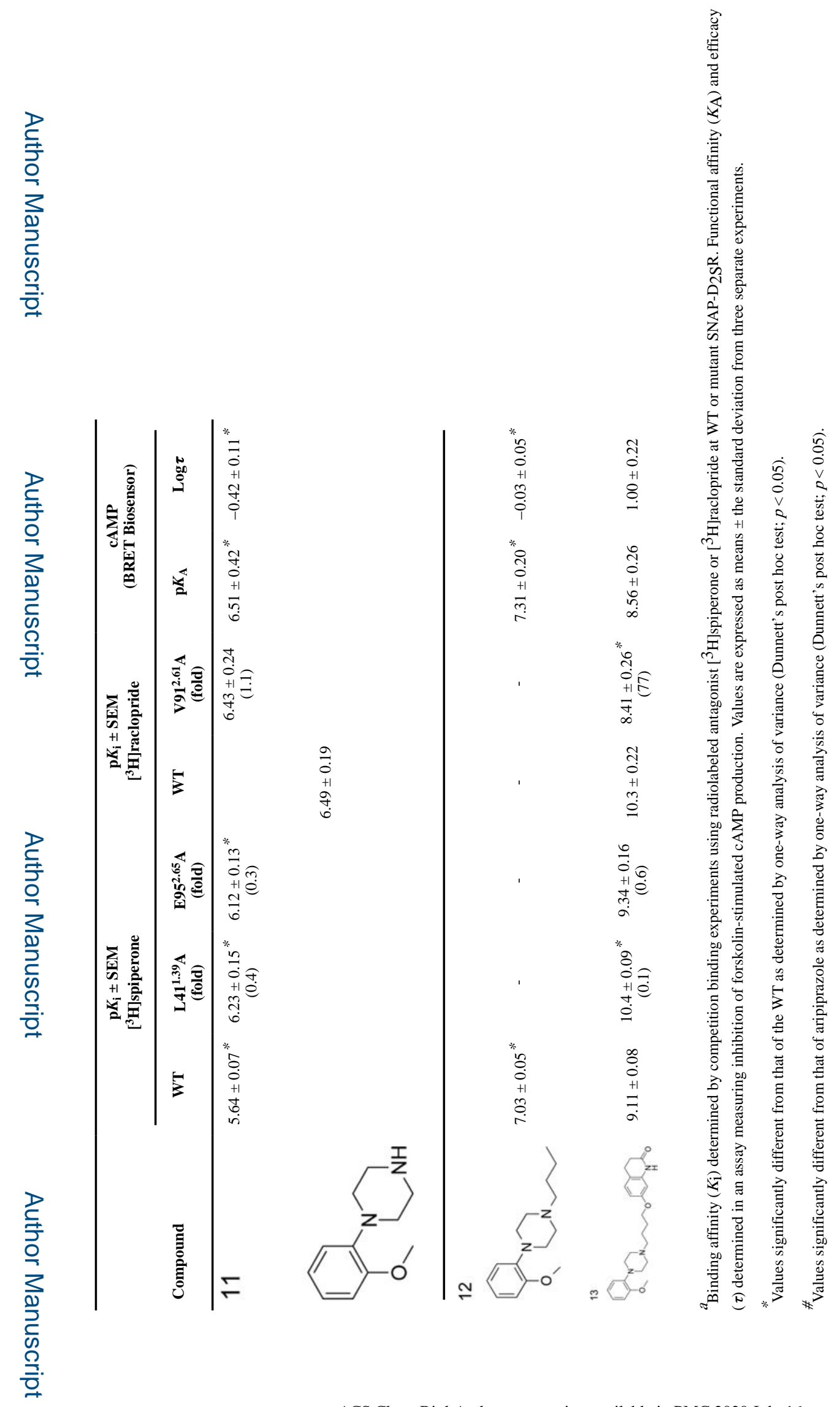

ACS Chem Biol. Author manuscript; available in PMC 2020 July 16. 


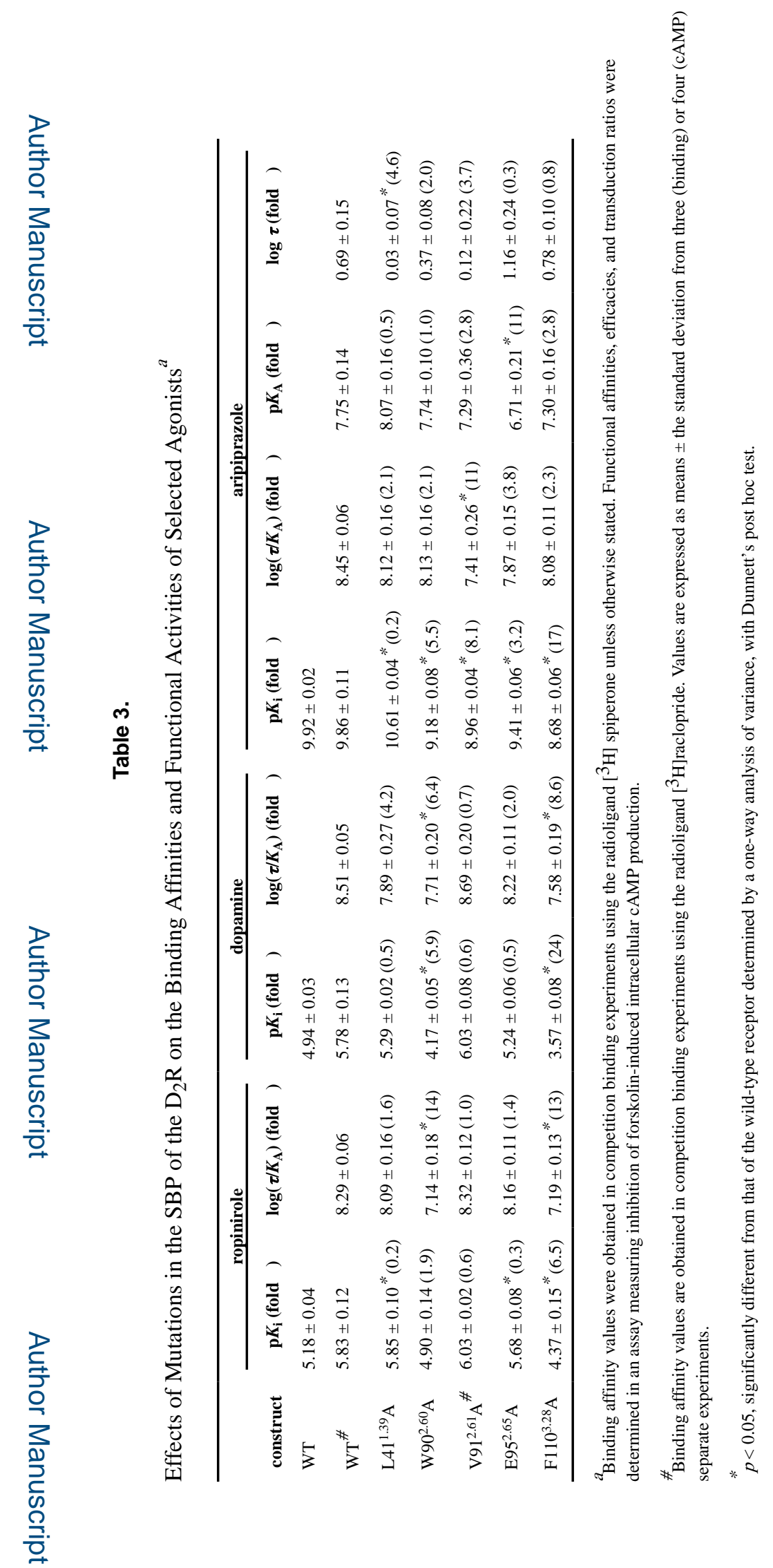

ACS Chem Biol. Author manuscript; available in PMC 2020 July 16. 